\title{
Functional Role of Adult Hippocampal Neurogenesis as a Therapeutic Strategy for Mental Disorders
}

\author{
Heechul Jun, ${ }^{1}$ Syed Mohammed Qasim Hussaini, ${ }^{1}$ Michael J. Rigby, ${ }^{2}$ and Mi-Hyeon Jang ${ }^{1,3}$ \\ ${ }^{1}$ Department of Neurologic Surgery, Mayo College of Medicine, 200 First Street SW, Rochester, MN 55905, USA \\ ${ }^{2}$ Summer Undergraduate Research Fellowship Program, Mayo Graduate School, Mayo College of Medicine, \\ 200 First Street SW, Rochester, MN 55905, USA \\ ${ }^{3}$ Department of Biochemistry and Molecular Biology, Mayo College of Medicine, 200 First Street SW, Rochester, MN 55905, USA
}

Correspondence should be addressed to Mi-Hyeon Jang, jang.mihyeon@mayo.edu

Received 15 September 2012; Revised 30 November 2012; Accepted 30 November 2012

Academic Editor: Chitra D. Mandyam

Copyright ( $) 2012$ Heechul Jun et al. This is an open access article distributed under the Creative Commons Attribution License, which permits unrestricted use, distribution, and reproduction in any medium, provided the original work is properly cited.

\begin{abstract}
Adult neurogenesis, the process of generating new neurons from neural stem cells, plays significant roles in synaptic plasticity, memory, and mood regulation. In the mammalian brain, it continues to occur well into adulthood in discrete regions, namely, the hippocampus and olfactory bulb. During the past decade, significant progress has been made in understanding the mechanisms regulating adult hippocampal neurogenesis and its role in the etiology of mental disorders. In addition, adult hippocampal neurogenesis is highly correlated with the remission of the antidepressant effect. In this paper, we discuss three major psychiatric disorders, depression, schizophrenia, and drug addiction, in light of preclinical evidence used in establishing the neurobiological significance of adult neurogenesis. We interpret the significance of these results and pose questions that remain unanswered. Potential treatments which include electroconvulsive therapy, deep brain stimulation, chemical antidepressants, and exercise therapy are discussed. While consensus lacks on specific mechanisms, we highlight evidence which indicates that these treatments may function via an increase in neural progenitor proliferation and changes to the hippocampal circuitry. Establishing a significant role of adult neurogenesis in the pathogenicity of psychiatric disorders may hold the key to potential strategies toward effective treatment.
\end{abstract}

\section{Introduction}

Mental disorders are debilitating conditions that significantly impair the function of the central nervous system and degrade the quality of life. About one-quarter of adult Americans are diagnosed with mental disorders such as major depression, anxiety, and schizophrenia [1]. Understanding the neurobiological basis of mental disorders, determining effective treatments, and alleviating the respective symptoms are major forces driving modern psychiatry today.

The hippocampus, an area of the brain important in memory, cognitive function, and mood regulation, is particularly vulnerable to chronic stress and mental disorders $[2,3]$. Several landmark clinical studies have demonstrated that major depression is accompanied by a decrease in the volume of hippocampus and consequent deficits in hippocampal function $[4,5]$. Similarly, in schizophrenic patients, shape deformations, cell loss, and volume reduction in the hippocampus were found using neuroimaging analysis [6-8]. Reversal of these alterations has successfully improved the behavioral and cognitive symptoms associated with these disorders. Such evidence has encouraged consideration of whether improving hippocampal structure and function could be a potential therapeutic target in treating mental disorders $[9,10]$.

Since the pioneering discovery of mammalian postnatal neurogenesis in the 1960s [58], adult neurogenesis has been unambiguously investigated in discrete brain regions across mammals including humans. Adult neurogenesis in all mammals, including humans, occurs throughout life within two specialized neurogenic niches, the subventricular zone (SVZ) of the lateral ventricle and the subgranular zone (SGZ) of the hippocampal dentate gyrus [59]. In particular, adult neurogenesis in dentate gyrus has attracted 
interest since newborn neurons contribute to enhanced neural plasticity that could sustain specific brain functions such as spatial learning, pattern discrimination, and mood regulation $[47,60,61]$. In addition, adult hippocampal neurogenesis in the mature brain represents a striking example of activity-dependent neural plasticity such as stress, antidepressants, and brain injuries [62]. Extensive studies have shown that voluntary exercise, enriched environments, and antidepressants contribute to overall brain health by robustly promoting adult hippocampal neurogenesis [37, 53, 63]. Decreased neurogenesis in the hippocampus via aging or stress has been implicated in the pathogenesis of cognitive deficits, anxiety and depression [64, 65]. In fact, adult hippocampal neurogenesis not only plays an important role in antidepressant action [47] but also plays a role in ameliorating various pathological disease conditions $[25,46$, $66,67]$. Therefore, a better understanding of the molecular and cellular mechanisms that regulate adult hippocampal neurogenesis may offer new therapeutic targets.

In this paper, we will highlight three major psychiatric disorders that have been associated with adult hippocampal neurogenesis. We will present and interpret the significance of the results in regards to the mechanism of cognitive and neurological disorders. Finally, we will lay out some current and potential therapeutic treatments that are used to counter these psychiatric disorders.

\section{Adult Neurogenesis and Mental Disorders}

2.1. Depression. Major depression is among the most prevalent psychiatric disorders and has high morbidity worldwide. Chronic stress represents a key risk factor in developing depression [68-70]. Despite a tremendous amount of study, the underlying mechanisms associated with the pathophysiology of depression remain poorly understood. The neurogenesis hypothesis of depression originated from studies using animal stress models. Because of the lack of a pathophysiologically reliable animal depression model, stress is primarily used to cause depression in animal models. These studies demonstrate that stress inhibits newborn neuron proliferation in the dentate gyrus of the hippocampus [71, 72]. All antidepressant classes are now known to promote adult hippocampal neurogenesis [38, 47]. The underlying cellular and molecular mechanisms of adult neurogenesis in regulating the suppressive effect of stress have been examined using various stress paradigms including physical and psychosocial stresses (Table 1). For example, physical stress such as repeated restraint [11] and inescapable foot shock [12] inhibits one or more steps of adult neurogenesis in the dentate gyrus. Similarly, chronic psychosocial stress using the social defeat paradigm leads to an inhibitory effect on cell proliferation and survival of newborn granule neurons in rodents [17]. In addition, the effect of depression on hippocampal volume in humans has been studied [4, 5, 73-75]. Early onset depression has been associated with a reduction in hippocampal volume [75], and in patients older than 60, depression has been associated specifically with a reduction in right hippocampal volume [74]. Further, hippocampal grey matter which undergoes reduction in depressed patients could be increased through antidepressive treatment like citalopram [73]. While such changes have been observed, postmortem studies have found no change in cell proliferation between major depression patients and control samples [76, 77]. Intriguingly, antidepressant treatment does increase cell proliferation in the dentate gyrus of major depression patients [77]. Such differential effects between rodents and humans on cell proliferation in the dentate gyrus might be due to biological differences implying different cellular mechanisms [78]. Determining the processes of adult neurogenesis in humans, such as fate determination, survival, differentiation, and integration across both spectrums will be helpful in reconciling the differences.

Preclinical models of depression generally show one or more suppressed steps during the sequential adult neurogenesis process. Such evidence has raised questions regarding the causality between neurogenesis and depression. Using a variety of methods ablating newborn neurons in the adult dentate gyrus, evidence correlates adult hippocampal neurogenesis with depression. However, the results are controversial [47, 48, 76, 79]. For example, ablating adult hippocampal neurogenesis using X-ray irradiation does not affect anxiety- and depressive-like behaviors as measured by novelty-suppressed feeding, open-field, light-dark, and elevated plus maze $[47,48,79]$. Further, pharmacological treatment with an anti-mitotic drug, methylazoxymethanol (MAM) which decreases cell proliferation in the dentate gyrus, does not induce an anhedonic-like state in rats [80]. On the contrary, genetically inhibiting hippocampal neurogenesis using Nestin-rtTA/Tet-Bax bigenic mice does increase anxiety-related behavior but does not affect depressivelike behavior [81]. Also, deletion of adult neurogenesis using GFAP-TK mice influences depressive-like behavioral response as shown by increased immobility time in the tail suspension test and induction of an anhedonic-like response in sucrose-preference test, but shows no effect in novelty-suppressed feeding or elevated plus maze [82]. This group further suggests that suppression of neurogenesis predisposes the animal to stress-induced anxiety/depressionlike behavior response and that newborn neurons in the hippocampus buffer this depressive-like behavior [82]. At this juncture, the results do not quite support that decreased neurogenesis is associated with a risk factor in development of depressive behavior. It may be more pertinent to conclude that newborn neurons may be a major contributor in normalizing or ameliorating against disease state rather than being causally involved in the etiology of depression in the animal model.

2.2. Schizophrenia. Schizophrenia is a multifactorial psychiatric disorder resulting from a complex interplay of genetic and environmental susceptibility factors [3]. Establishing the major etiology, neuropathology and pathophysiology of schizophrenia have proven difficult.

Initial studies from postmortem hippocampal tissue have indicated a reduction in neural progenitors and hippocampal volume in patients diagnosed with schizophrenia 


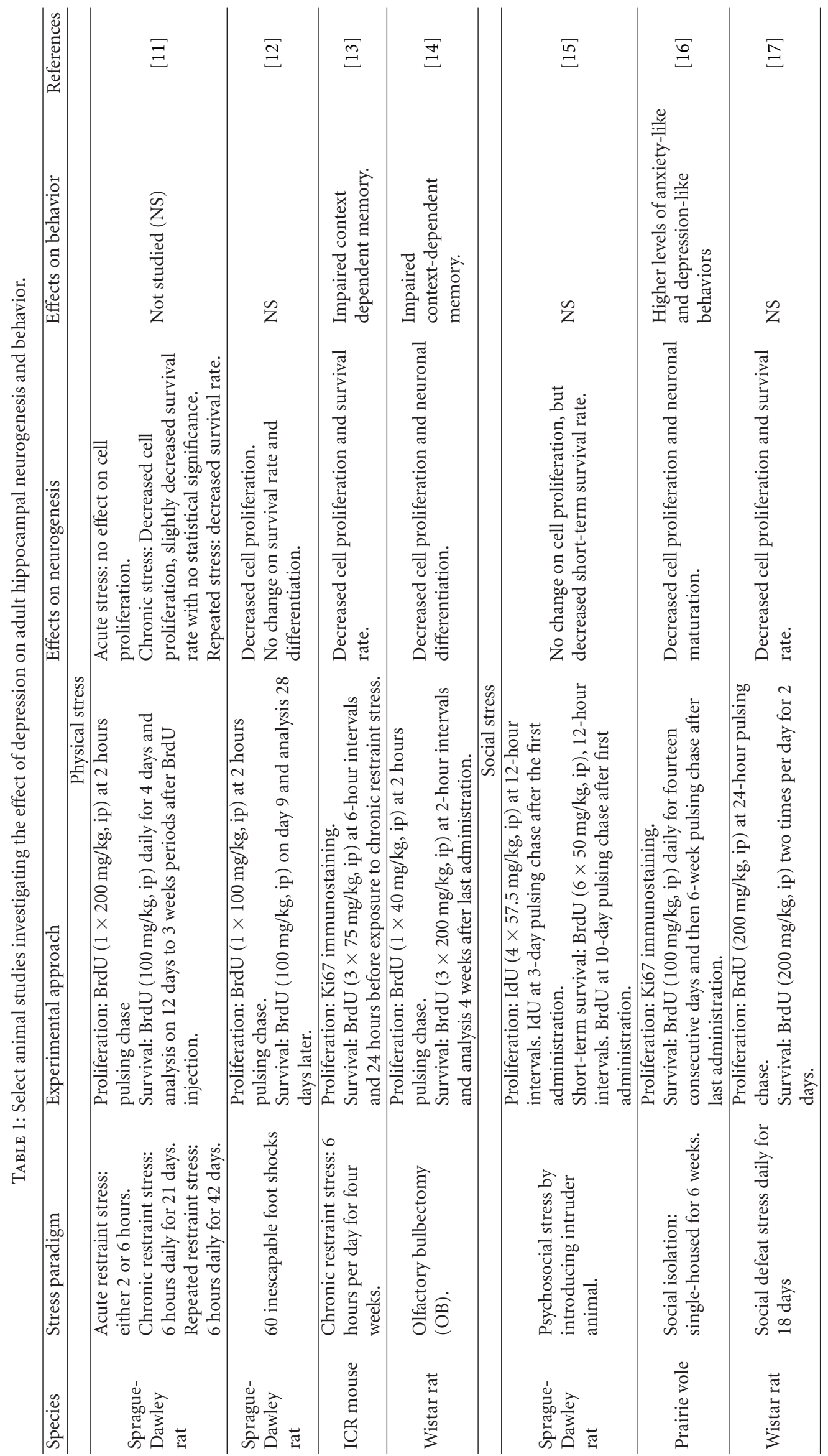


[76]. Supporting this, a growing number of studies have identified susceptibility genes associated with schizophrenia that are involved in regulation of adult neurogenesis [22, 83] (Table 2). One such gene is disrupted-in-schizophrenia 1 (DISC1) which was originally identified as a potential susceptibility gene for schizophrenia and related psychiatric disorders in a large Scottish pedigree $[84,85]$. It is widely expressed during embryonic neurogenesis and postnatal development with high expression persisting in the adult hippocampus, especially in the dentate gyrus $[86,87]$. The expression pattern of DISC1 may implicate a role of DISC1 in neuronal development. Using various approaches including genetic mutants and short-hairpin RNA (shRNA) knockdown, several lines of evidence have converged to indicate that DISC1 function is involved in distinct steps of adult neurogenesis and behavioral response. First, mutant DISC1 mice with selective impairment in working memory showed reduced number of neural progenitors and immature neurons, as well as misoriented apical dendrites of immature neurons in the adult hippocampal dentate gyrus [21]. In the same DISC1 mutant mice, altered axonal targeting and short-term plasticity in the hippocampus were also observed [21]. Second, knockdown of DISC1 via lentiviralmediated shRNA also led to decreased newborn cells and a depressive-like behavioral response [22]. Third, knockdown of DISC1 via retroviral-mediated shRNA approach to label dividing cells and their progeny results in aberrant dendritic development including an enhancement of dendritic outgrowth, soma hypertrophy, overextended migration, accelerated synapse formation, mistargeted axonal mossy fibers, and presynaptic differentiation of newborn granule neurons in the adult mouse dentate gyrus $[18,19]$. Further, the same group also indicated that AKT-mTOR signaling pathway is a critical DISC1 target in regulating dendritic development of newborn granule neurons in the adult dentate gyrus [88]. Taken together, these results suggest that DISC1 orchestrates the tempo of functional integration in the adult brain. It also demonstrates the major roles a susceptibility gene could play in neuronal development and the pathogenesis of the disease.

Other susceptibility genes for schizophrenia linked to adult neurogenesis have been identified. NPAS, a bHLH transcription factor that is broadly expressed in the developing neuroepithelium, was identified as a risk factor for schizophrenia and associated with cognitive deficits in an affected mother and her daughter [89, 90]. Mice lacking Npas 3 show developmental brain abnormalities including a reduction in size of the anterior hippocampus, hypoplasia of the corpus callosum and enlargement of the ventricles [23]. In addition, mice lacking Npas3 exhibit behavioral abnormalities including locomotor hyperactivity, subtle gait defects, impairment of prepulse inhibition of acoustic startle, deficit in recognition memory, and altered anxiety-related responses [23]. Finally, Npas3-deficent mice also display a significant reduction of adult neurogenesis by $84 \%$ relative to their wild-type littermates, which may suggest that adult neurogenesis impairment is involved in the pathogenesis of schizophrenia [22]. However, direct causal evidence linking adult neurogenesis to schizophrenia needs to be examined.
In addition to using genetic animal models for schizophrenia, a prenatal injection of synthetic double-stranded RNA polyriboinosinic polyribocytidylic acid (PolyI:C) into mice has been used as an animal model for schizophrenia $[26,91]$. These mice displayed behavioral deficits in the open-field test and prepulse inhibition of the startle response [26]. A recent study demonstrated that these infected animals showed behavioral impairments accompanied by decreased adult hippocampal neurogenesis [25]. Interestingly, these abnormalities were rescued by increasing adult hippocampal neurogenesis via exercise, indicating that enhancing neurogenesis may help aid recovery for schizophrenia [25].

2.3. Drug Addiction. Drug addiction is a chronic relapsing disorder characterized by a loss of the ability to control drug intake and a compulsive drug-seeking and -taking behavior [92]. Generally, the mesolimbic dopaminergic system in the brain is thought to be an important brain area in the neurobiology of addiction [93]. The hippocampus has received great attention because abusive drugs are potent negative regulators of adult hippocampal neurogenesis and as a result may impair cognitive function [27, 94-96] (Table 3).

Cocaine abuse, a powerful and addictive psychostimulant drug, is associated with dynamic regulation of adult neurogenesis in the hippocampal dentate gyrus and its corresponding memory function [30]. Studies have shown that both a high dose of cocaine or chronic cocaine exposure can decrease the proliferation of neural progenitors in the rat dentate gyrus [28] and cause working memory dysfunction [30]. In addition, chronic treatment of cocaine increased adult neurogenesis in mice in some studies [97], but the same effect is not observed in the rat dentate gyrus [27, 31, 98, 99]. While most studies support evidence that chronic administration of cocaine diminishes proliferation of neural progenitors in the adult hippocampus, the effect on survival and maturation of neural progenitors is not always consistent. Possible explanations for the discrepancy might be due to the differences in animal strain, methods, and duration of cocaine treatment. Therefore, more evidence is needed to determine the timing, duration and consequences of impaired adult hippocampal neurogenesis caused by cocaine. Recently, role of adult hippocampal neurogenesis in cocaine-taking and cocaine-seeking behavior was explored. Using X-ray irradiation approach, ablation of adult hippocampal neurogenesis increased cocaine-taking and cocaine-seeking behavior, suggesting that impaired neurogenesis may result in increased susceptibility in the animal model of cocaine addiction [100]. Interestingly, withdrawal from cocaine administration normalizes the reduction of neural progenitors and enhances maturation of neural progenitors in the adult dentate gyrus [27]. This indicates that the normalization of the cocaineinduced neurogenesis deficit may help decrease susceptibility to relapse and related cognitive deficits.

The correlation between alcohol dependence and hippocampal neurogenesis has been extensively studied. Among other anatomic changes, alcoholic patients undergo structural changes in hippocampal volume [101-103]. Animal models have been used to examine the cellular effects and 


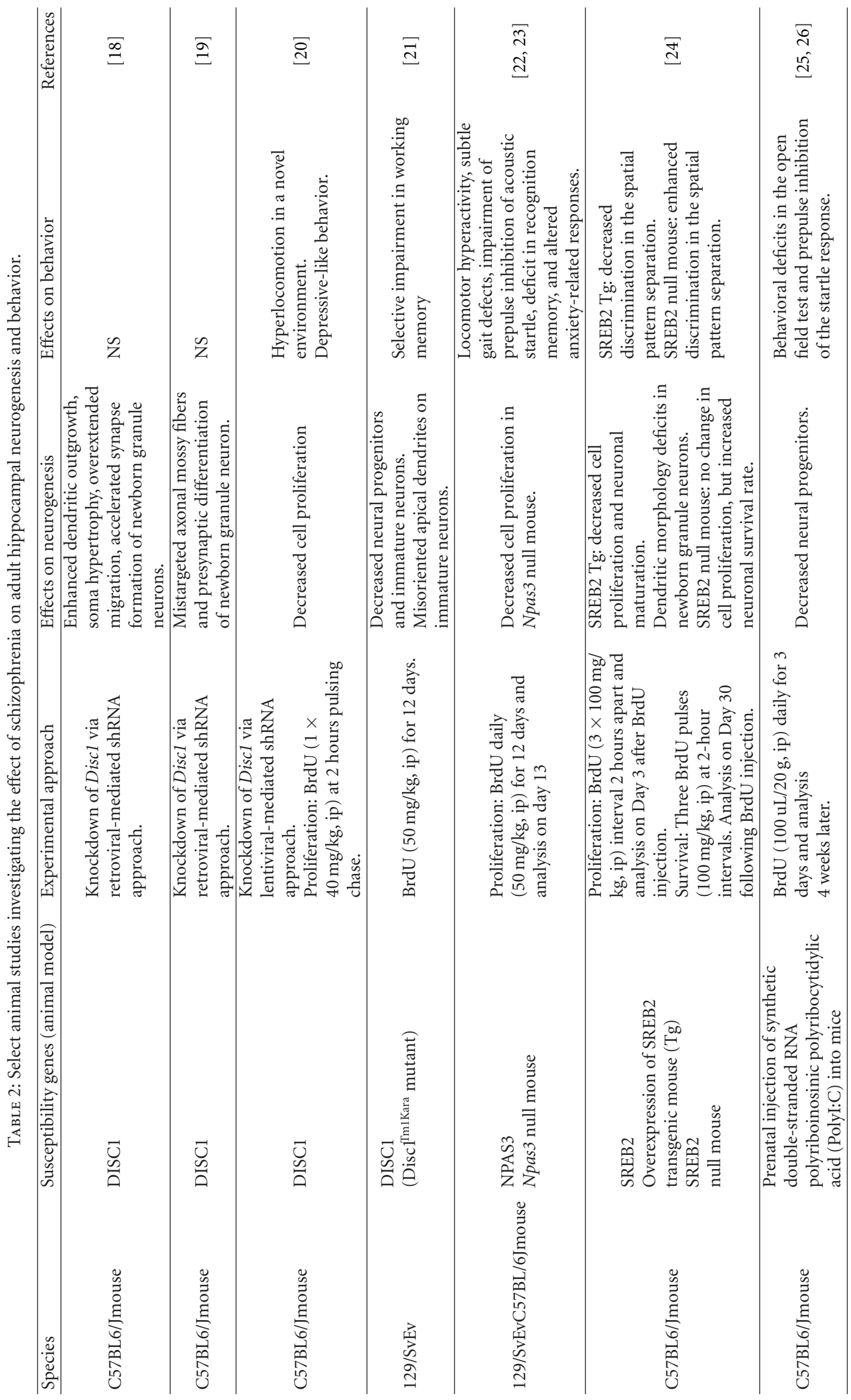




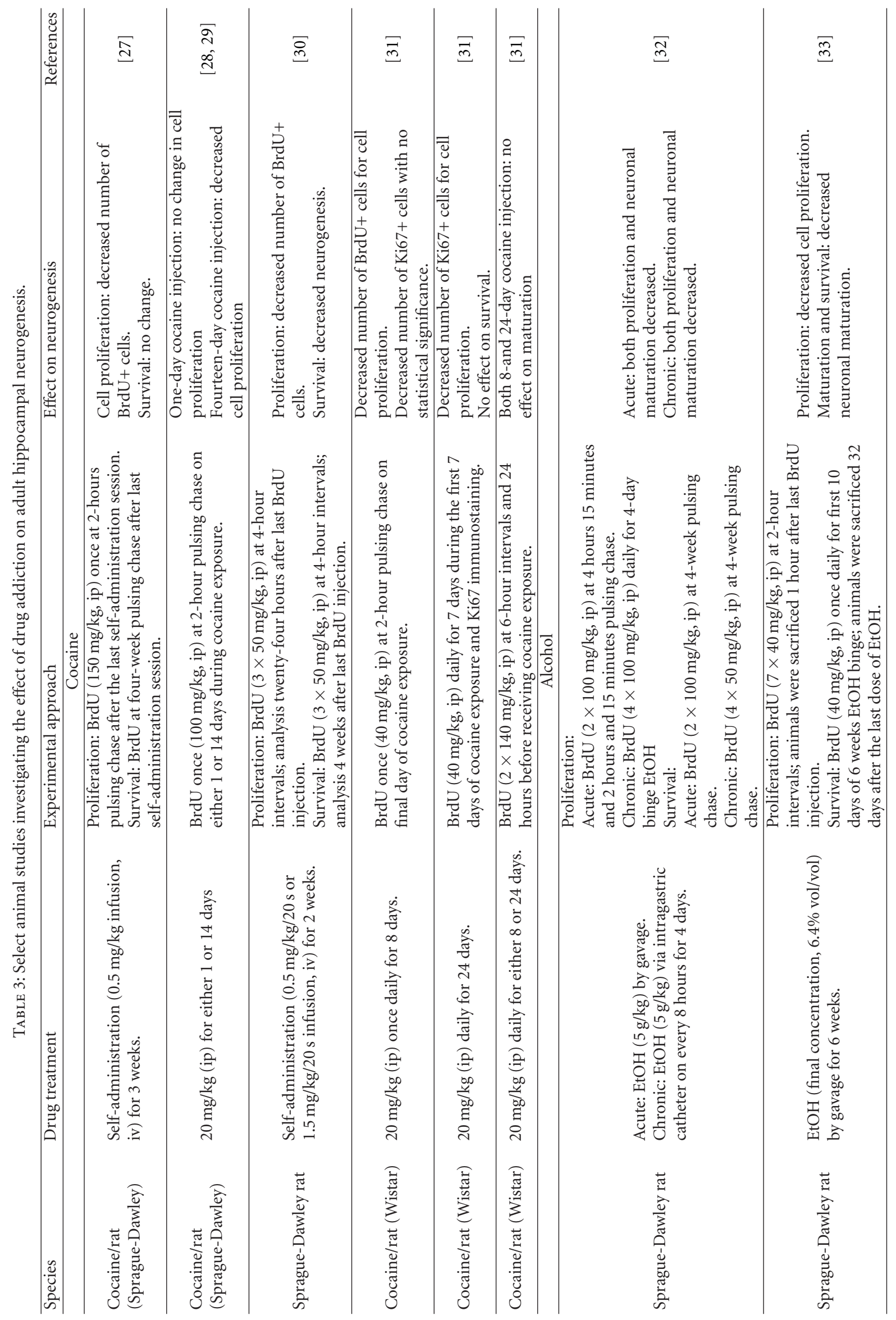




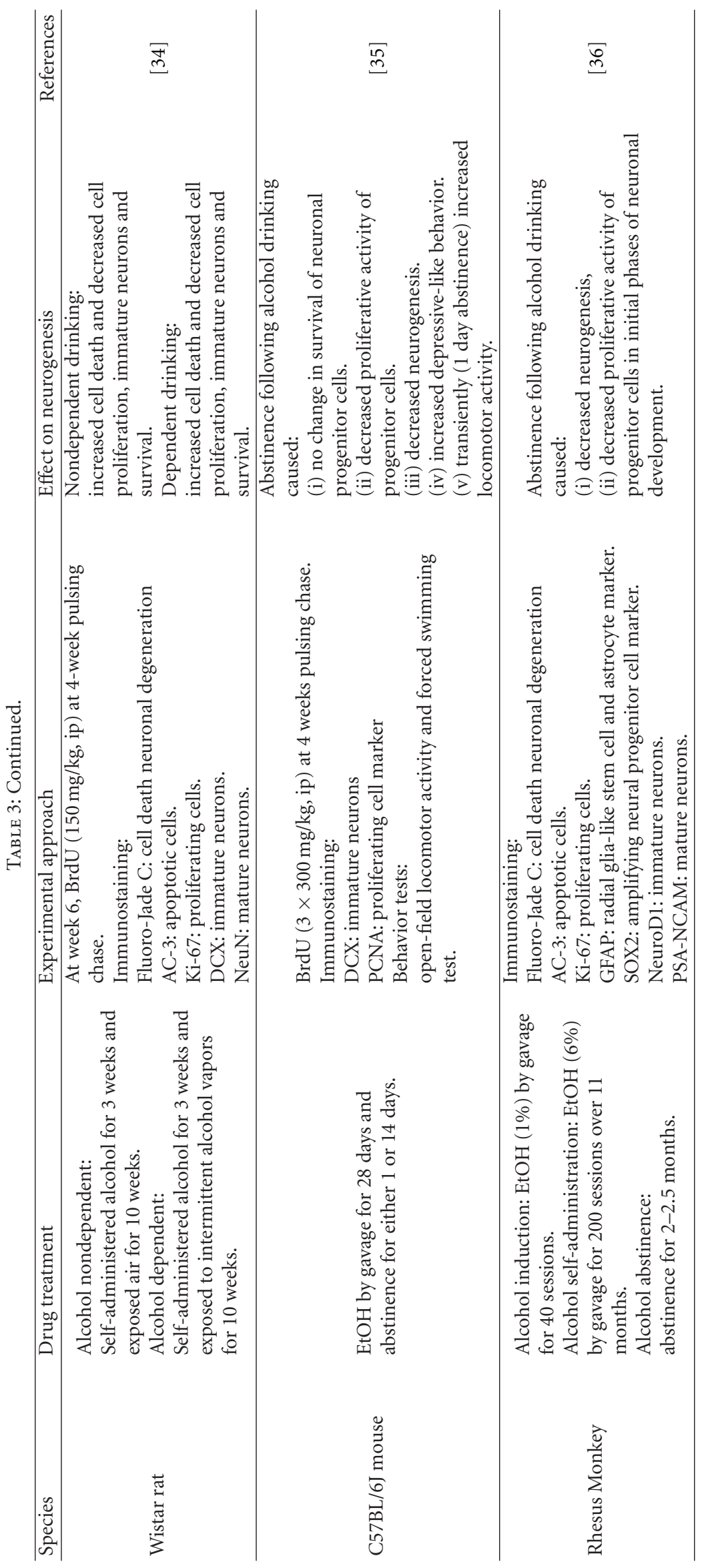


underlying mechanisms. Converging studies have associated alcohol consumption and dependence with a selective decline in adult hippocampal neurogenesis [32, 104-107]. Acute or chronic administration of ethanol treatment in mice inhibits neural progenitor cell proliferation and survival in the adult rat hippocampus $[32,108]$. Clinically relevant animal models have been used to confirm this wherein alcohol dependence reduced proliferation of neural progenitors, as well as consequent differentiation and maturation [34]. More recently, chronic alcohol treatment over 11 months in adolescent macaque monkeys produced selective and long-lasting decrease in hippocampal neural progenitor proliferation [36]. Alterations in synaptic plasticity are also associated with chronic alcohol treatment resulting in the reversible inhibition of long-term potentiation (LTP) in the rat hippocampus [109]. Besides LTP changes, functional or behavioral changes as measured via active avoidance, and spatial memory also occur following alcohol consumption indicating learning and memory deficits $[110,111]$. An abstinence state following alcohol consumption can contribute to depression-like behavior with a concurrent reduction in the neural progenitor and immature neuron population in dentate gyrus in mice [35]. This was counteracted via desipramine which alleviated both the structural and functional phenotypes associated with this comorbidity [35]. Whether adult neurogenesis can regulate alcohol-drinking or -seeking behavior remains to be studied. Understanding this causality will allow us to develop improved therapeutic intervention in treating the pathological symptoms associated with alcohol dependence.

\section{Therapeutic Interventions}

Adult neurogenesis is affected by a variety of external stimuli that influence neuronal activity. The therapeutic effects of electroconvulsive therapy, antidepressants, exercise, and others such as deep brain stimulation have been utilized for their therapeutic efficacy. These have been associated with adult hippocampal neurogenesis and will be discussed below.

\subsection{Electroconvulsive Therapy and Deep Brain Stimulation.} One of the more intense therapeutic treatments for severe psychiatric disorders, especially depression, is electroconvulsive therapy (ECT) [112]. In the 1940s and 50s, ECT was used in extreme cases in humans when patients did not respond to other treatments $[112,113]$. Despite extensive research, the mechanism of action of ECT had not been discovered. Recently, it was linked to neurogenesis, providing a possible explanation for the mechanism that helps to relieve symptoms [37, 38] (Table 4).

The first study to demonstrate the influence of ECT on adult hippocampal neurogenesis showed that a single treatment of ECT results in stimulation of adult neural progenitors that survive up to 3 months afterward [37]. A subsequent study confirmed that ECT promotes neural progenitor proliferation [38]. Further, ECT also reversed longterm neurogenesis deficits and hippocampal-dependent fear memory disrupted by X-ray irradiation [114]. This matches clinical observations that ECT is the most effective treatment for depression. It may also suggest that adult hippocampal neurogenesis is a critical neurobiological component underlying the clinical effect of ECT. A detailed characterization of hippocampal progenitors affected by ECT has been reported. At the cellular level, ECT stimulates proliferation of quiescent progenitor cells and at a later phase increases the proliferation of amplifying progenitor cells [39], which may lead to a net increase in the number of mature adult-born neurons [40]. Functionally, electrophysiological analysis shows that chronic treatment of ECT induces longterm-potentiation-(LTP-) like synaptic changes in the adult dentate gyrus [115]. Given that LTP results in increased proliferation of neural progenitors in the dentate gyrus [116], enhanced neurogenesis caused by ECT could potentially alter hippocampal circuitry which may contribute to the functional effects of ECT.

Exactly how ECT stimulates specific niche signals to regulate the sequential process of adult neurogenesis remains unclear. Growing evidence in the past decade has determined a number of factors that regulate adult neurogenesis in response to ECT in the hippocampus. Among those factors, induction of neurotrophic growth factors has been extensively identified. These include brain-derived neurotrophic factor (BDNF), fibroblast growth factor-2 (FGF2 ), and vascular endothelial growth factor (VEGF) [105, $106,117]$. BDNF, a member of the nerve growth factor family expressed throughout the brain, is known to be responsible for synaptic strength, survival, and growth of mature neurons via activation of its receptor TrkB. While both acute and chronic treatments of ECT induce BDNF and TrkB gene expression, the level of BDNF gene expression remains prolonged during chronic treatment of ECT [106]. FGF family of growth factors and corresponding receptors are involved in angiogenesis and early stages of neural development [118, 119]. Expression of FGF-2 mRNA in rodent hippocampus is increased in both acute and chronic treatments of ECT [117]. In addition, infusion of BDNF and FGF into rodent hippocampus results in antidepressantlike effects $[120,121]$, while blockade of BDNF and FGF in the dentate gyrus induces behavioral deficits and decreases adult hippocampal neurogenesis $[121,122]$. These findings indicate that such factors can be strong candidates in ECT treatment to mediate antidepressant effects. A recent study demonstrated ECT promoting DNA demethylation in the BDNF and FGF promoter regions and adult neurogenesis in dentate gyrus through growth arrest and DNA-damageinducible protein 45 beta (Gadd45b) [42]. These results suggest that dynamic epigenetic DNA modifications may serve as an essential mechanism to translate neurogenic niche signals for sustained regulation of adult neurogenesis and antidepressant action of ECT. Lastly, VEGF is known as a regulator for vascular growth and also a stimulator of neurogenesis [123]. The effect of ECT is dependent upon VEGF signaling for induction of quiescent neural progenitor cell proliferation and is sufficient to produce an antidepressant effect [39]. Taken together, ECT is one of the strongest stimuli of hippocampal neurogenesis. It increases the rate of proliferation and maturation of new neurons in 


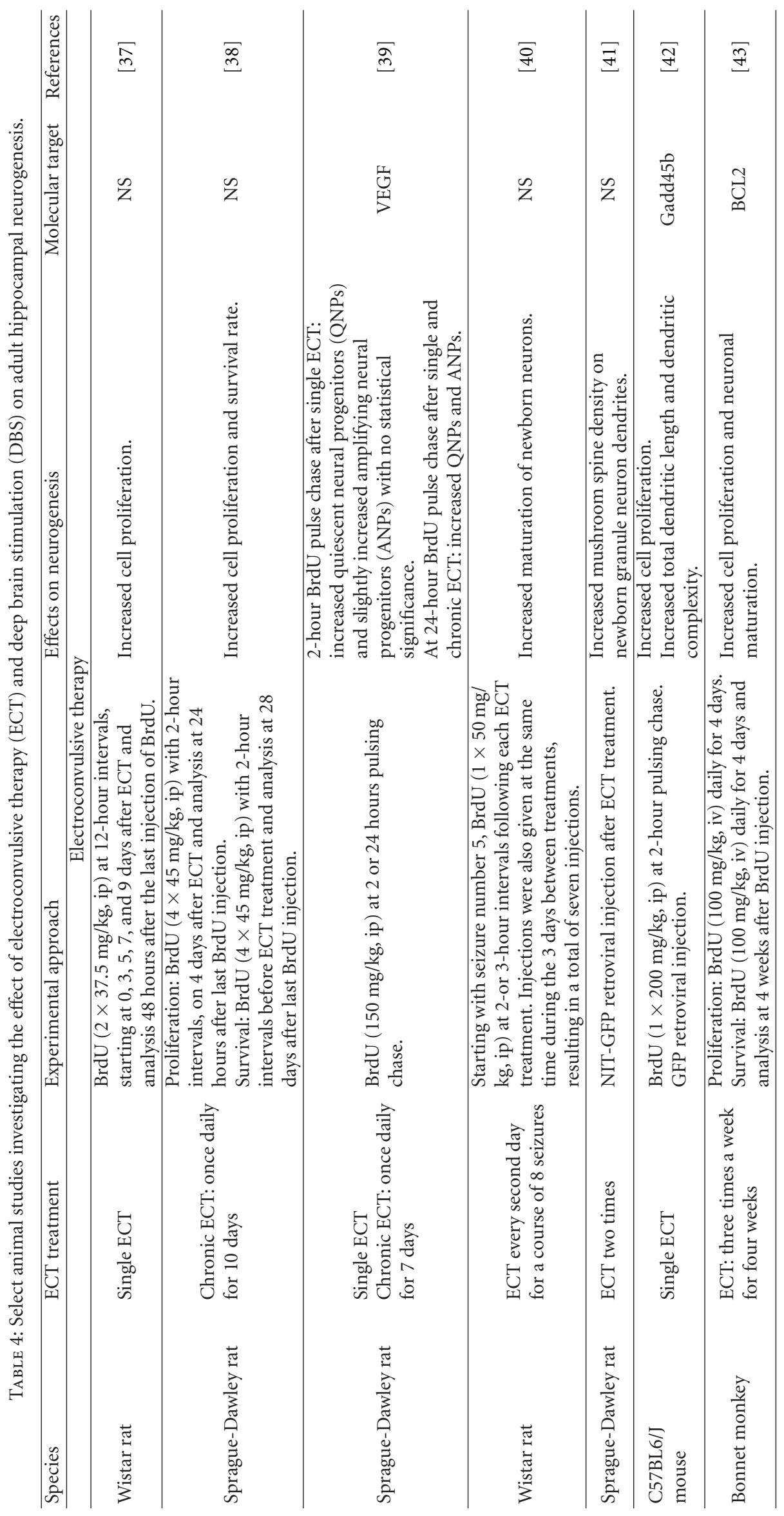




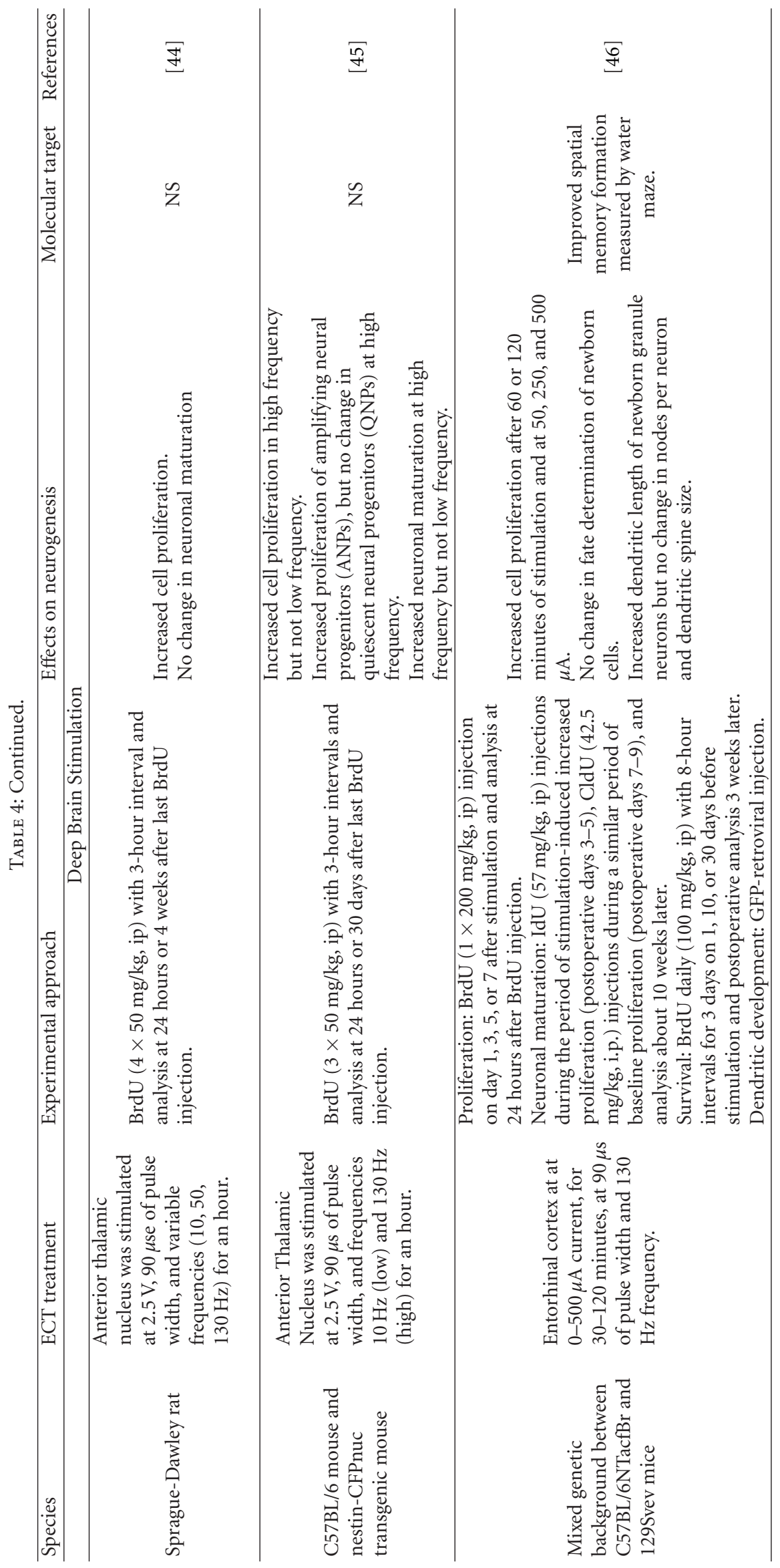


the dentate gyrus which could have a significant effect on hippocampal circuitry. ECT's therapeutic efficacy may be a result of this, proving to be an effective treatment for severe depression and other mood disorders.

Another possible treatment for neuropsychiatric disorders is deep brain stimulation (DBS). DBS is an extreme treatment for a wide range of neurological disorders such as Parkinson's disease, dystonia, chronic pain, and tremors [124]. It has proven effective in treating these disorders in initial trials $[125,126]$ and also in treating major depression especially in patients that do not respond to chemical antidepressants [127]. Growing evidence has focused on multiple anatomical targets in the brain with different stimulation frequencies, pulse width, and amplitude in order to obtain the ideal setting for conferring an antidepressant response (Table 4). The limited number of studies that have been conducted thus far suggests that DBS may proceed via an increase in adult neurogenesis and survival rate of mature neurons integrating into the hippocampal circuitry (Table 4). The first evidence reported by [44] demonstrated that high frequency stimulation of the rat thalamus increased adult neurogenesis and restored experimentally suppressed neurogenesis in the dentate gyrus. One study shows that stimulation of the anterior thalamic nuclei has the effect of promoting proliferation of ANPs, similar to fluoxetine [45]. Similarly, other studies have identified specific stimulation of the entorhinal cortex, a major source of input to the hippocampus, promoting proliferation of progenitors which increase the survival rate and formation of mature neurons integrating into the hippocampal circuitry [46]. This finding was supported by increased performance in the water-maze memory tests. DBS may prove to be a significant approach in combating psychiatric disorders. However, direct involvement of adult neurogenesis conferring antidepressant action of DBS as well as its mechanism of action needs to be determined.

3.2. Chronic Treatment of Chemical Antidepressants. Multiple classes of antidepressants have been shown to positively influence aspects of adult hippocampal neurogenesis in a chronic time course manner (Table 5). Most selective serotonin reuptake inhibitor (SSRI) treatments are associated with a delayed onset of therapeutic efficacy consistent with the time course of maturation of newborn neurons [66]. Stimulation of neurogenesis is required for antidepressant efficacy. Studies in monkeys and rodents confirm that in conferring antidepressant action, chronic fluoxetine treatment stimulates adult hippocampal neurogenesis and mediated depressive-like behavioral effects $[38,47,116]$.

The cellular basis of fluoxetine action within the neuronal differentiation cascade has been identified. Using a nestincyan fluorescent protein (CFP)nuc mouse line where the reporter is fused to a nuclear localization signal that allows identification and classification of early neuronal progenitors, fluoxetine was shown to increase symmetric divisions of the amplifying neuronal progenitor (ANP) cell class while not affecting division of stem-like cells in the dentate gyrus [49]. These results suggest that the cellular target for fluoxetine's therapeutic action to increase new neurons arises due to a resultant expansion of this ANP cell class. Another study by Wang et al. [48] showed that fluoxetine stimulates dendritic development of newborn neurons and neurogenesis-dependent LTP in the dentate gyrus which results in behavioral alteration induced by fluoxetine. By ablating adult neurogenesis using X-ray irradiation, they indicated that fluoxetine-induced LTP and behavior response both require adult hippocampal neurogenesis [17]. Thus, the effects of chronic fluoxetine administration on the maturation and functional properties of newborn neurons may translate into enhanced synaptic plasticity in the appropriate neural circuits, which subsequently exhibit a behavioral response to antidepressant action. Besides studying fluoxetine, various other classes of antidepressant drugs have been tested. For instance, similar results were seen in rodent administration of SSRI citalopram [50] and tricyclic antidepressant imipramine [51], although this effect was observed in the stressed condition. The mood stabilizers including lithium have been shown to significantly increase both neural progenitors and survival [128]. Although a more detailed characterization of the cellular process needs to be determined, these studies support the notion that regulation of adult neurogenesis may provide potential therapeutic targets for treatment of depression.

What underlies the neurogenic action of antidepressants? Extrinsic factors such as BDNF and VEGF that regulate the microniche of adult neurogenesis may hold the answer. BDNF serves as a key regulator of various aspects in adult hippocampal neurogenesis including proliferation, survival, dendritic growth, maturation, and synaptic plasticity, which could make BDNF a potential mediator of the antidepressant action induced by different chemical antidepressants [129]. Emerging evidence shows that BDNF and TrkB mRNA levels in the hippocampus are dramatically induced by chronic treatment of different chemical antidepressants including fluoxetine, tranylcypromine, sertraline, desipramine, and mianserin [130]. Infusion of exogenous BDNF into the hippocampus exhibits antidepressive-like behavioral responses [120]. Further, behavioral abnormalities found in heterozygous $\mathrm{BDNF}(\mathrm{BDNF}+/-)$ mice and mice lacking the TrkB are counteracted by chronic antidepressants including fluoxetine [131]. This data coupled with evidence that BDNF-signaling enhances adult neurogenesis in the dentate gyrus [132] led to the suggestion that antidepressants may represent an enhancement of neural plasticity such as adult neurogenesis and behavioral alteration, which in turn could be regulated by increasing the level of BDNF [130]. However, a direct link between adult hippocampal neurogenesis and antidepressive-like behavioral action of antidepressants through BDNF is still lacking.

The other promising molecular target is VEGF, which shows increased mRNA levels with chronic treatment of fluoxetine and desipramine in the hippocampus [133]. VEGF is also sufficient to promote basal level of adult hippocampal neurogenesis [134] and is necessary for the antidepressant action [133]. Conversely, a significant role of VEGF is demonstrated when VEGF signaling diminishes induction of adult neurogenesis and antidepressant action in response to chronic treatment of fluoxetine [133]. Taken together, 


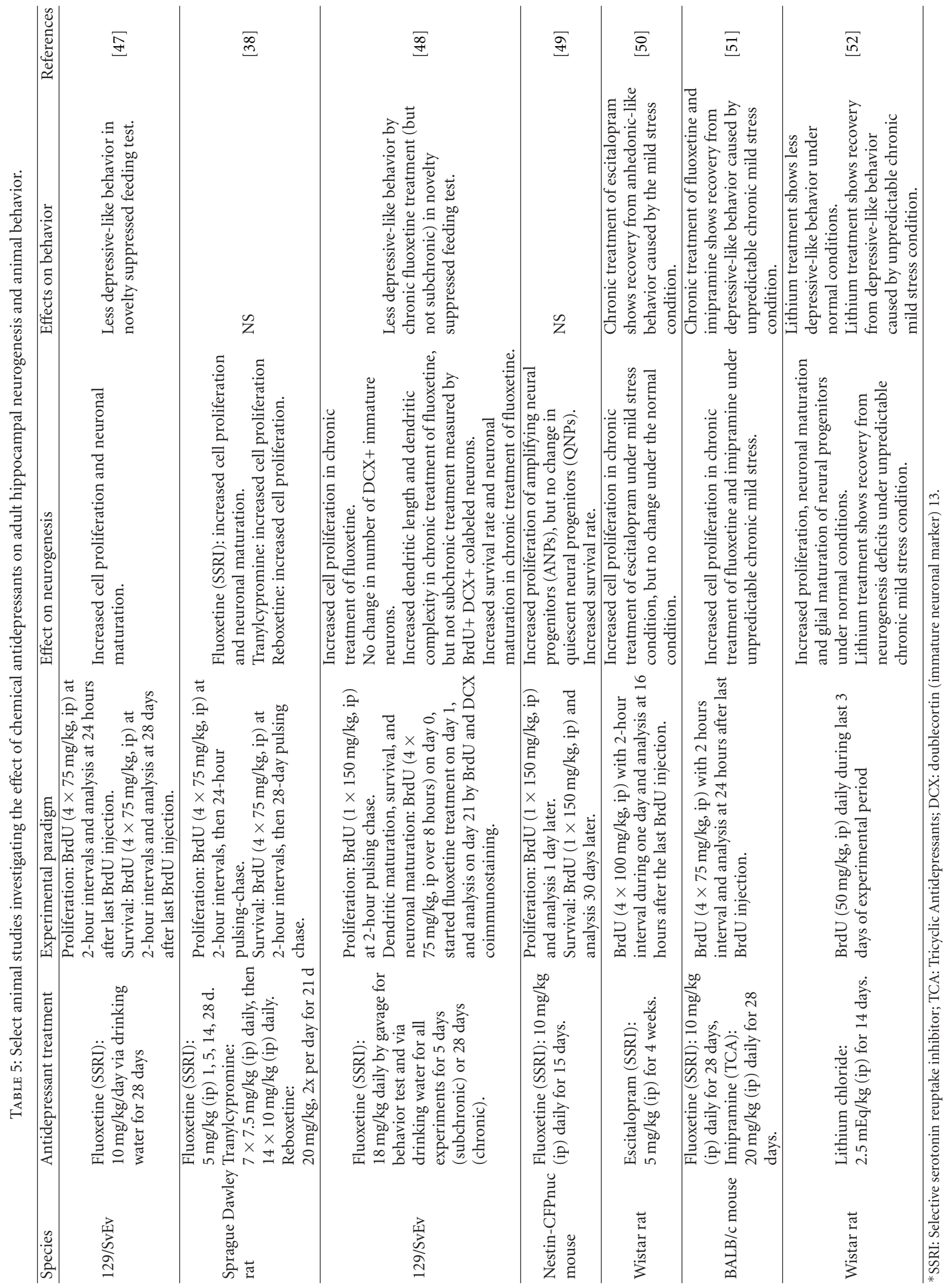


an important action of antidepressants may be to increase neurogenesis in the hippocampus through a variety of molecular mechanisms which have an impact on depressive symptoms.

3.3. Exercise Therapy. Physiological stimulation in the form of exercise has been shown to stimulate cell proliferation and adult hippocampal neurogenesis $[53,55,56,135]$ and enhance the learning and memory function in both mice $[57,136]$ and human [137]. The plastic nature of the mammalian brain, especially neurogenesis continuing in the hippocampus well into adulthood, has allowed for exercise to exert its effects at the cellular level. This not only holds promise for brain diseases such as Alzheimer's or Parkinson's disease, but also for schizophrenia and major depression. A recent clinical trial demonstrated how exercise therapy can improve the mental health and cardiovascular fitness in patients with schizophrenia [138]. The use of exercise in treating depression has also received increased attention in recent years.

The cellular effects of running on hippocampal neurogenesis have been closely investigated in a number of notable studies (Table 6). Using BrdU labeling, one of the earlier studies showed how mice with free access to a running wheel nearly doubled the number of surviving newborn cells [53]. Another study has shown that running actually activates the quiescent radial population in the hippocampus [55]. These activated cells eventually give rise to mature neurons that are functionally integrated into the hippocampal circuitry. Hippocampal structure and function has been closely studied in relation to cognitive or mental function. Running has been shown to improve neurogenesis with a corresponding enhancement in learning and longterm potentiation $[57,136]$. Physical exercise has all been implicated in the distinct encoding of spatial information. In one study, young and aged mice undergoing running exercise were compared to each other with the result that running enhanced spatial pattern separation when exercise was correlated with increased hippocampal neurogenesis [56]. The effect of exercise-induced neurogenesis has been studied in humans as well. Cerebral blood volume (CBV) maps in hippocampal formation have been generated in both exercising mice and humans [54]. Similar to mice, exercise specifically targeted the dentate gyrus CBV in humans and was correlated with increased cognitive function.

It is still unclear whether benefits from physical exercise, namely, in cognitive function, are conferred by the increase in neurogenesis. Any causal relationship between the increased neurogenesis and benefits in learning and memory is still being studied, and at least, current evidence is not decisive [139]. BDNF, as previously noted playing a role in both ECT and antidepressants, has again been suggested as a strong contender and possible mediator of the causal relationship being observed. A recent clinical trial demonstrated that exercise training increased hippocampal volume, effectively reversing age-related loss in volume [137]. This increased hippocampal volume was also associated with greater serum levels of BDNF [137]. In the review of
Bekinschetein et al., a number of studies are mentioned indicating a strong causal link between BDNF and learning and memory. Physical activity has been associated with increased BDNF mRNA levels in the rat hippocampus, especially the dentate gyrus $[140,141]$. Specific deletion of the BDNF-receptor TrkB reduced survival of newborn neurons, impaired neurogenesis-dependent LTP, and increased anxiety-like behavior [142]. Indeed, ablation of $\operatorname{TrkB}$ in neural progenitors also prevented behavioral improvements conferred by exercise [132], bolstering the role of BDNF. Other factors, namely, NMDA receptors and downstream effectors such as calcium/calmodulin protein kinase II and mitogen-activated protein kinase, could be involved in the mechanism by which BDNF effects synaptic plasticity [143]. Further evidence may ascertain the mechanism by which BDNF operates.

In an effort to treat neuropsychiatric disorders in relation to aberrant neurogenesis, it is important to study and classify important stimuli that can have a lasting effect on neurogenesis and hippocampal function. ECT, DBS, antidepressants, and physical exercise all seem to have their own effect on neurogenesis, and in combination with proper administration, they could prove vital in discovering potential treatments for psychiatric disorders that continue to disable the population.

\section{Conclusion}

Significant progress has been made in the past decade documenting the function and regulation of adult neurogenesis. Many offer a neurobiological understanding of the role of adult neurogenesis in psychiatric disorders. These studies demonstrate how these disorders may proceed through an impairment of neural progenitor proliferation in the hippocampus, and how an ablation of neurogenesis may predispose an animal to depressive-like behaviors. A pathophysiologically reliable animal model is, however, still required to confirm data across the cellular and behavioral spectrums. Further, genetic manipulations of susceptibility genes in loss-of-function transgenic models may be used to rescue cognitive deficits and confirm their roles via cellular and behavioral studies. These may bolster a causal link between adult neurogenesis and the disorder.

However, with our current knowledge, several questions remain to be answered. We do not yet have a clear understanding of how external stimuli in current treatments mediate the induction and function of factors in the neurogenic niche that stimulate adult hippocampal neurogenesis. We also do not know how the regulation of neurogenic niche via niche signals and neurotrophic factors may be altered by X-ray irradiation which is used to ablate and study neurogenesis. The role of BDNF has been evidenced in ECT, DBS, antidepressants, and exercise therapy. Going forward, its downstream effects would need to be studied to determine how BDNF mediates synaptic plasticity. Further, in the case of relatively new treatments such as DBS, conclusive evidence of its antidepressant effect and mechanism of action will bolster the significant role it could play in treating psychiatric 


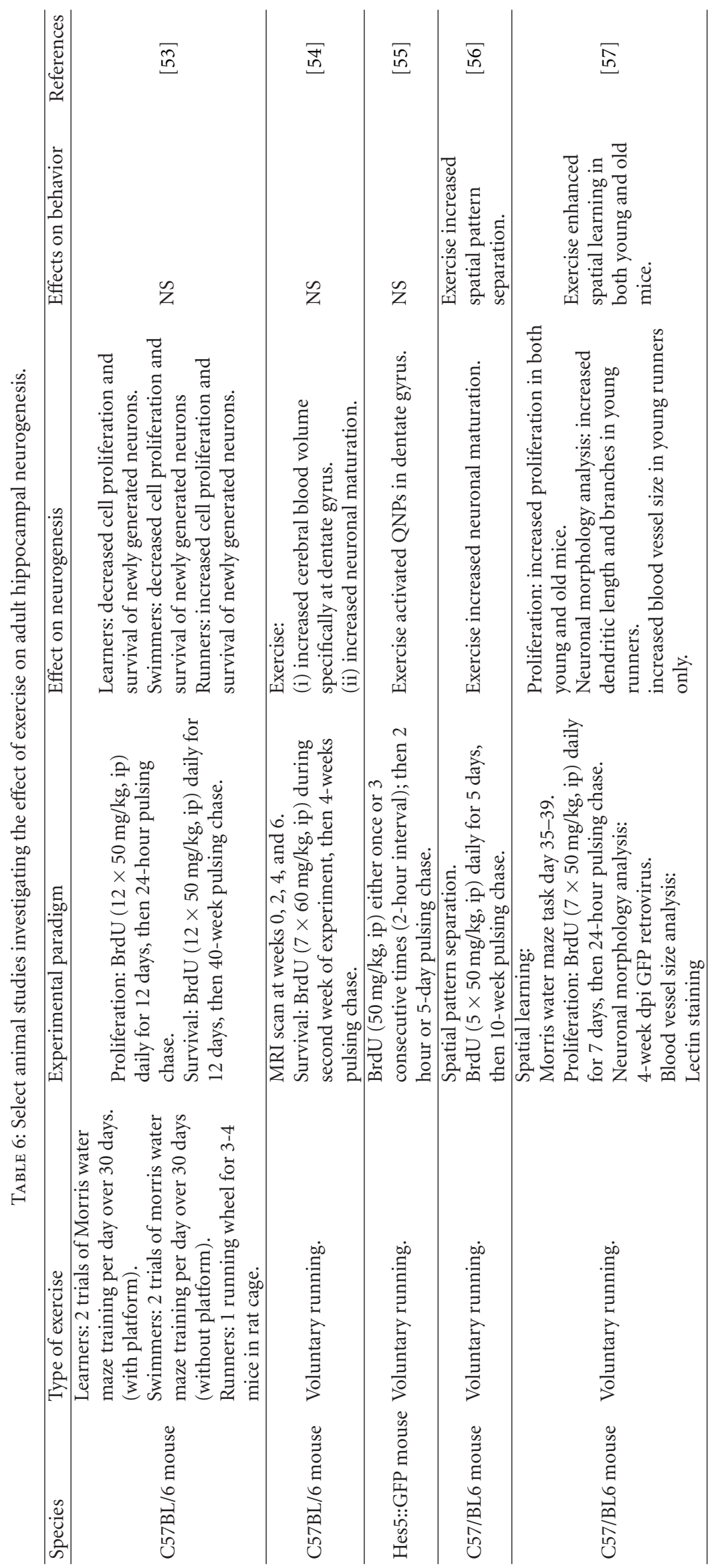


disorders. Finally, we are yet to obtain a conclusive causal relationship between adult neurogenesis and depression, as well as adult neurogenesis and cognitive function or learning and memory. How drug abuse may alter these relationships especially in the maturation and integration of newborn neurons in the hippocampus will be useful. Current evidence when coupled to such a characterization may provide evidence of the cellular mechanism at play in many widely used treatments.

Adult neurogenesis is important in synaptic plasticity with overarching roles in memory, learning, and mood. Such roles have been established via a plethora of studies which show that the process is dynamically regulated and demonstrates striking structural plasticity in response to internal and environmental cues. It is strongly regulated by stress signals, and stimulated by antidepressants, which may serve to potentially alter the hippocampal circuitry. Current evidence indicates a significant role for adult neurogenesis in the neurological impairments of psychiatric disorders. At this critical juncture, it is important we distinguish whether adult neurogenesis is causally involved in the etiology or plays a significant role in ameliorating the disease state symptoms. A clear understanding of this relationship in regard to the pathogenesis of the disease will be invaluable in aiding our understanding of the causes at play, and how effective treatments may be designed to alleviate the symptoms.

\section{Authors' Contribution}

H. Jun and S. Hussaini contributed equally to this work.

\section{Acknowledgments}

The authors would like to thank Dr. Hongjun Song for suggestions. The research in Dr. Jang laboratory was supported by NIH (R00MH090115), NARSAD (Young Investigator Award), start-up funds from Mayo foundation to M. H. Jang, and by a Summer Undergraduate Research Fellowship from Mayo Graduate School to M. J. Rigby.

\section{References}

[1] R. C. Kessler, W. T. Chiu, O. Demler, K. R. Merikangas, and E. E. Walters, "Prevalence, severity, and comorbidity of 12-month DSM-IV disorders in the National Comorbidity Survey Replication," Archives of General Psychiatry, vol. 62, no. 6, pp. 617-627, 2005.

[2] Y. Li, Y. Mu, and F. H. Gage, "Development of neural circuits in the adult hippocampus," Current Topics in Developmental Biology, vol. 87, pp. 149-174, 2009.

[3] D. R. Weinberger, "Cell biology of the hippocampal formation in schizophrenia," Biological Psychiatry, vol. 45, no. 4, pp. 395-402, 1999.

[4] Y. I. Sheline, P. W. Wang, M. H. Gado, J. G. Csernansky, and M. W. Vannier, "Hippocampal atrophy in recurrent major depression," Proceedings of the National Academy of Sciences of the United States of America, vol. 93, no. 9, pp. 3908-3913, 1996.

[5] J. D. Bremner, M. Narayan, E. R. Anderson, L. H. Staib, H. L. Miller, and D. S. Charney, "Hippocampal volume reduction in major depression," The American Journal of Psychiatry, vol. 157, no. 1, pp. 115-118, 2000.

[6] M. D. Nelson, A. J. Saykin, L. A. Flashman, and H. J. Riordan, "Hippocampal volume reduction in schizophrenia as assessed by magnetic resonance imaging: a meta-analytic study," Archives of General Psychiatry, vol. 55, no. 5, pp. 433440, 1998.

[7] J. G. Csernansky, S. Joshi, L. Wang et al., "Hippocampal morphometry in schizophrenia by high dimensional brain mapping," Proceedings of the National Academy of Sciences of the United States of America, vol. 95, no. 19, pp. 11406-11411, 1998.

[8] S. Heckers, "Neuroimaging studies of the hippocampus in schizophrenia," Hippocampus, vol. 11, no. 5, pp. 520-528, 2001.

[9] V. Dhikav and K. S. Anand, "Is hippocampal atrophy a future drug target?" Medical Hypotheses, vol. 68, no. 6, pp. 13001306, 2007.

[10] N. A. DeCarolis and A. J. Eisch, "Hippocampal neurogenesis as a target for the treatment of mental illness: a critical evaluation," Neuropharmacology, vol. 58, no. 6, pp. 884-893, 2010.

[11] K. Pham, J. Nacher, P. R. Hof, and B. S. McEwen, "Repeated restraint stress suppresses neurogenesis and induces biphasic PSA-NCAM expression in the adult rat dentate gyrus," European Journal of Neuroscience, vol. 17, no. 4, pp. 879-886, 2003.

[12] J. E. Malberg and R. S. Duman, "Cell proliferation in adult hippocampus is decreased by inescapable stress: reversal by fluoxetine treatment," Neuropsychopharmacology, vol. 28, no. 9, pp. 1562-1571, 2003.

[13] J. Yun, H. Koike, D. Ibi et al., "Chronic restraint stress impairs neurogenesis and hippocampus-dependent fear memory in mice: possible involvement of a brain-specific transcription factor Npas4," Journal of Neurochemistry, vol. 114, no. 6, pp. 1840-1851, 2010.

[14] K. Jaako-Movits and A. Zharkovsky, "Impaired fear memory and decreased hippocampal neurogenesis following olfactory bulbectomy in rats," European Journal of Neuroscience, vol. 22, no. 11, pp. 2871-2878, 2005.

[15] R. M. Thomas, G. Hotsenpiller, and D. A. Peterson, "Acute psychosocial stress reduces cell survival in adult hippocampal neurogenesis without altering proliferation," The Journal of Neuroscience, vol. 27, no. 11, pp. 2734-2743, 2007.

[16] C. Lieberwirth, Y. Liu, X. Jia, and Z. Wang, "Social isolation impairs adult neurogenesis in the limbic system and alters behaviors in female prairie voles," Hormones and Behavior, vol. 62 , no. 4, pp. 357-366, 2012.

[17] B. Czéh, T. Welt, A. K. Fischer et al., "Chronic psychosocial stress and concomitant repetitive transcranial magnetic stimulation: effects on stress hormone levels and adult hippocampal neurogenesis," Biological Psychiatry, vol. 52, no. 11, pp. 1057-1065, 2002.

[18] X. Duan, J. H. Chang, S. Ge et al., "Disrupted-in-schizophrenia 1 regulates integration of newly generated neurons in the adult brain," Cell, vol. 130, no. 6, pp. 1146-1158, 2007.

[19] R. L. Faulkner, M. H. Jang, X. B. Liu et al., "Development of hippocampal mossy fiber synaptic outputs by new neurons in the adult brain," Proceedings of the National Academy of Sciences of the United States of America, vol. 105, no. 37, pp. 14157-14162, 2008.

[20] Y. Mao, X. Ge, C. L. Frank et al., "Disrupted in schizophrenia 1 regulates neuronal progenitor proliferation via modulation 
of GSK3 $\beta / \beta$-catenin signaling," Cell, vol. 136, no. 6, pp. 10171031, 2009.

[21] M. Kvajo, H. McKellar, L. J. Drew et al., "Altered axonal targeting and short-term plasticity in the hippocampus of Disc1 mutant mice," Proceedings of the National Academy of Sciences of the United States of America, vol. 108, no. 49, pp. E1349-E1358, 2011.

[22] A. A. Pieper, X. Wu, T. W. Han et al., "The neuronal PAS domain protein 3 transcription factor controls FGFmediated adult hippocampal neurogenesis in mice," Proceedings of the National Academy of Sciences of the United States of America, vol. 102, no. 39, pp. 14052-14057, 2005.

[23] E. W. Brunskill, L. A. Ehrman, M. T. Williams et al., "Abnormal neurodevelopment, neurosignaling and behaviour in Npas3-deficient mice," European Journal of Neuroscience, vol. 22, no. 6, pp. 1265-1276, 2005.

[24] Q. Chen, J. H. Kogan, A. K. Gross et al., "SREB2/GPR85, a schizophrenia risk factor, negatively regulates hippocampal adult neurogenesis and neurogenesis-dependent learning and memory," European Journal of Neuroscience, vol. 36, no. 5, pp. 2597-2608, 2012.

[25] S. A. Wolf, A. Melnik, and G. Kempermann, "Physical exercise increases adult neurogenesis and telomerase activity, and improves behavioral deficits in a mouse model of schizophrenia," Brain, Behavior, and Immunity, vol. 25, no. 5, pp. 971-980, 2011.

[26] S. E. P. Smith, J. Li, K. Garbett, K. Mirnics, and P. H. Patterson, "Maternal immune activation alters fetal brain development through interleukin-6," The Journal of Neuroscience, vol. 27, no. 40, pp. 10695-10702, 2007.

[27] M. A. Noonan, K. H. Choi, D. W. Self, and A. J. Eisch, "Withdrawal from cocaine self-administration normalizes deficits in proliferation and enhances maturity of adult-generated hippocampal neurons," The Journal of Neuroscience, vol. 28, no. 10, pp. 2516-2526, 2008.

[28] M. Yamaguchi, T. Suzuki, T. Seki et al., "Repetitive cocaine administration decreases neurogenesis in adult rat hippocampus," Annals of the New York Academy of Sciences, vol. 1025, pp. 351-362, 2004.

[29] M. Yamaguchi, T. Suzuki, T. Seki et al., "Decreased cell proliferation in the dentate gyrus of rats after repeated administration of cocaine," Synapse, vol. 58, no. 2, pp. 63-71, 2005.

[30] E. Sudai, O. Croitoru, A. Shaldubina et al., "High cocaine dosage decreases neurogenesis in the hippocampus and impairs working memory," Addiction Biology, vol. 16, no. 2, pp. 251-260, 2011.

[31] L. Domínguez-Escribà, V. Hernández-Rabaza, M. SorianoNavarro et al., "Chronic cocaine exposure impairs progenitor proliferation but spares survival and maturation of neural precursors in adult rat dentate gyrus," European Journal of Neuroscience, vol. 24, no. 2, pp. 586-594, 2006.

[32] K. Nixon and F. T. Crews, "Binge ethanol exposure decreases neurogenesis in adult rat hippocampus," Journal of Neurochemistry, vol. 83, no. 5, pp. 1087-1093, 2002.

[33] D. G. Herrera, A. G. Yagüe, S. Johnsen-Soriano et al., "Selective impairment of hippocampal neurogenesis by chronic alcoholism: protective effects of an antioxidant," Proceedings of the National Academy of Sciences of the United States of America, vol. 100, no. 13, pp. 7919-7924, 2003.

[34] H. N. Richardson, S. H. Chan, E. F. Crawford et al., "Permanent impairment of birth and survival of cortical and hippocampal proliferating cells following excessive drinking during alcohol dependence," Neurobiology of Disease, vol. 36, no. 1, pp. 1-10, 2009.

[35] J. R. Stevenson, J. P. Schroeder, K. Nixon, J. Besheer, F. T. Crews, and C. W. Hodge, "Abstinence following alcohol drinking produces depression-like behavior and reduced hippocampal neurogenesis in mice," Neuropsychopharmacology, vol. 34, no. 5, pp. 1209-1222, 2009.

[36] M. A. Taffe, R. W. Kotzebue, R. D. Crean, E. F. Crawford, S. Edwards, and C. D. Mandyam, "Long-lasting reduction in hippocampal neurogenesis by alcohol consumption in adolescent nonhuman primates," Proceedings of the National Academy of Sciences of the United States of America, vol. 107, no. 24, pp. 11104-11109, 2010.

[37] T. M. Madsen, A. Treschow, J. Bengzon, T. G. Bolwig, O. Lindvall, and A. Tingstrom, "Increased neurogenesis in a model of electroconvulsive therapy," Biological Psychiatry, vol. 47, no. 12, pp. 1043-1049, 2000.

[38] J. E. Malberg, A. J. Eisch, E. J. Nestler, and R. S. Duman, "Chronic antidepressant treatment increases neurogenesis in adult rat hippocampus," The Journal of Neuroscience, vol. 20, no. 24, pp. 9104-9110, 2000.

[39] E. Segi-Nishida, J. L. Warner-Schmidt, and R. S. Duman, "Electroconvulsive seizure and VEGF increase the proliferation of neural stem-like cells in rat hippocampus," Proceedings of the National Academy of Sciences of the United States of America, vol. 105, no. 32, pp. 11352-11357, 2008.

[40] B. W. Scott, J. M. Wojtowicz, and W. M. Burnham, "Neurogenesis in the dentate gyrus of the rat following electroconvulsive shock seizures," Experimental Neurology, vol. 165, no. 2, pp. 231-236, 2000.

[41] C. Zhao, J. Warner-Schmidt, R. S. Duman, and F. H. Gage, "Electroconvulsive seizure promotes spine maturation in newborn dentate granule cells in adult rat," Developmental Neurobiology, vol. 72, no. 6, pp. 937-942, 2012.

[42] D. K. Ma, M. H. Jang, J. U. Guo et al., "Neuronal activityinduced Gadd45b promotes epigenetic DNA demethylation and adult neurogenesis," Science, vol. 323, no. 5917, pp. 1074-1077, 2009.

[43] T. D. Perera, J. D. Coplan, S. H. Lisanby et al., "Antidepressant-induced neurogenesis in the hippocampus of adult nonhuman primates," The Journal of Neuroscience, vol. 27, no. 18, pp. 4894-4901, 2007.

[44] H. Toda, C. Hamani, A. P. Fawcett, W. D. Hutchison, and A. M. Lozano, "The regulation of adult rodent hippocampal neurogenesis by deep brain stimulation: laboratory investigation," Journal of Neurosurgery, vol. 108, no. 1, pp. 132-138, 2008.

[45] J. M. Encinas, C. Hamani, A. M. Lozano, and G. Enikolopov, "Neurogenic hippocampal targets of deep brain stimulation," The Journal of Comparative Neurology, vol. 519, no. 1, pp. 620, 2011.

[46] S. S. Stone, C. M. Teixeira, L. M. Devito et al., "Stimulation of entorhinal cortex promotes adult neurogenesis and facilitates spatial memory," The Journal of Neuroscience, vol. 31, no. 38, pp. 13469-13484, 2011.

[47] L. Santarelli, M. Saxe, C. Gross et al., "Requirement of hippocampal neurogenesis for the behavioral effects of antidepressants," Science, vol. 301, no. 5634, pp. 805-809, 2003.

[48] J. W. Wang, D. J. David, J. E. Monckton, F. Battaglia, and R. Hen, "Chronic fluoxetine stimulates maturation and synaptic plasticity of adult-born hippocampal granule cells," The Journal of Neuroscience, vol. 28, no. 6, pp. 1374-1384, 2008. 
[49] J. M. Encinas, A. Vaahtokari, and G. Enikolopov, "Fluoxetine targets early progenitor cells in the adult brain," Proceedings of the National Academy of Sciences of the United States of America, vol. 103, no. 21, pp. 8233-8238, 2006.

[50] M. N. Jayatissa, C. Bisgaard, A. Tingström, M. Papp, and O. Wiborg, "Hippocampal cytogenesis correlates to escitalopram-mediated recovery in a chronic mild stress rat model of depression," Neuropsychopharmacology, vol. 31, no. 11, pp. 2395-2404, 2006.

[51] A. Surget, M. Saxe, S. Leman et al., "Drug-dependent requirement of hippocampal neurogenesis in a model of depression and of antidepressant reversal," Biological Psychiatry, vol. 64, no. 4, pp. 293-301, 2008.

[52] G. Chen, G. Rajkowska, F. Du, N. Seraji-Bozorgzad, and H. K. Manji, "Enhancement of hippocampal neurogenesis by lithium," Journal of Neurochemistry, vol. 75, no. 4, pp. 17291734, 2000.

[53] H. van Praag, G. Kempermann, and F. H. Gage, "Running increases cell proliferation and neurogenesis in the adult mouse dentate gyrus," Nature Neuroscience, vol. 2, no. 3, pp. 266-270, 1999.

[54] A. C. Pereira, D. E. Huddleston, A. M. Brickman et al., "An in vivo correlate of exercise-induced neurogenesis in the adult dentate gyrus," Proceedings of the National Academy of Sciences of the United States of America, vol. 104, no. 13, pp. 5638-5643, 2007.

[55] S. Lugert, O. Basak, P. Knuckles et al., "Quiescent and active hippocampal neural stem cells with distinct morphologies respond selectively to physiological and pathological stimuli and aging," Cell Stem Cell, vol. 6, no. 5, pp. 445-456, 2010.

[56] D. J. Creer, C. Romberg, L. M. Saksida, H. van Praag, and T. J. Bussey, "Running enhances spatial pattern separation in mice," Proceedings of the National Academy of Sciences of the United States of America, vol. 107, no. 5, pp. 2367-2372, 2010.

[57] H. van Praag, T. Shubert, C. Zhao, and F. H. Gage, "Exercise enhances learning and hippocampal neurogenesis in aged mice," The Journal of Neuroscience, vol. 25, no. 38, pp. 86808685, 2005.

[58] J. Altman and G. D. Das, "Autoradiographic and histological evidence of postnatal hippocampal neurogenesis in rats," The Journal of Comparative Neurology, vol. 124, no. 3, pp. 319335, 1965.

[59] G. L. Ming and H. Song, "Adult neurogenesis in the mammalian central nervous system," Annual Review of Neuroscience, vol. 28, pp. 223-250, 2005.

[60] C. D. Clelland, M. Choi, C. Romberg et al., "A functional role for adult hippocampal neurogenesis in spatial pattern separation," Science, vol. 325, no. 5937, pp. 210-213, 2009.

[61] A. Sahay, K. N. Scobie, A. S. Hill et al., "Increasing adult hippocampal neurogenesis is sufficient to improve pattern separation," Nature, vol. 472, no. 7344, pp. 466-470, 2011.

[62] D. K. Ma, W. R. Kim, G. L. Ming, and H. Song, "Activitydependent extrinsic regulation of adult olfactory bulb and hippocampal neurogenesis," Annals of the New York Academy of Sciences, vol. 1170, pp. 664-673, 2009.

[63] H. van Praag, G. Kempermann, and F. H. Gage, "Neural consequences of environmental enrichment," Nature Reviews Neuroscience, vol. 1, no. 3, pp. 191-198, 2000.

[64] D. C. Lie, H. Song, S. A. Colamarino, G. L. Ming, and F. H. Gage, "Neurogenesis in the adult brain: new strategies for central nervous system diseases," Annual Review of Pharmacology and Toxicology, vol. 44, pp. 399-421, 2004.

[65] C. Mirescu and E. Gould, "Stress and adult neurogenesis," Hippocampus, vol. 16, no. 3, pp. 233-238, 2006.
[66] A. Sahay and R. Hen, "Adult hippocampal neurogenesis in depression," Nature Neuroscience, vol. 10, no. 9, pp. 11101115, 2007.

[67] J. Veena, B. N. Srikumar, K. Mahati, T. R. Raju, and B. S. Shankaranarayana Rao, "Oxotremorine treatment restores hippocampal neurogenesis and ameliorates depression-like behaviour in chronically stressed rats," Psychopharmacology, vol. 217, no. 2, pp. 239-253, 2011.

[68] K. S. Kendler, L. M. Karkowski, and C. A. Prescott, "Causal relationship between stressful life events and the onset of major depression," The American Journal of Psychiatry, vol. 156, no. 6, pp. 837-841, 1999.

[69] T. L. Bale, "Stress sensitivity and the development of affective disorders," Hormones and Behavior, vol. 50, no. 4, pp. 529533, 2006.

[70] M. V. Schmidt, S. H. Scharf, V. Sterlemann et al., "High susceptibility to chronic social stress is associated with a depression-like phenotype," Psychoneuroendocrinology, vol. 35, no. 5, pp. 635-643, 2010.

[71] E. Gould, B. S. McEwen, P. Tanapat, L. A. M. Galea, and E. Fuchs, "Neurogenesis in the dentate gyrus of the adult tree shrew is regulated by psychosocial stress and NMDA receptor activation," The Journal of Neuroscience, vol. 17, no. 7, pp. 2492-2498, 1997.

[72] E. Gould, P. Tanapat, B. S. Mcewen, G. Flügge, and E. Fuchs, "Proliferation of granule cell precursors in the dentate gyrus of adult monkeys is diminished by stress," Proceedings of the National Academy of Sciences of the United States of America, vol. 95, no. 6, pp. 3168-3171, 1998.

[73] D. Arnone, S. McKie, R. Elliott et al., "State-dependent changes in hippocampal grey matter indepression," Molecular Psychiatry. In press.

[74] K. Sawyer, E. Corsentino, N. Sachs-Ericsson, and D. C. Steffens, "Depression, hippocampal volume changes, and cognitive decline in a clinical sample of older depressed outpatients and non-depressed controls," Aging \& Mental Health, vol. 16, no. 6, pp. 753-762, 2012.

[75] C. E. Sexton, M. Le Masurier, C. L. Allan et al., "Magnetic resonance imaging in late-life depression: vascular and glucocorticoid cascade hypotheses," The British Journal of Psychiatry, vol. 201, no. 1, pp. 46-51, 2012.

[76] A. Reif, S. Fritzen, M. Finger et al., "Neural stem cell proliferation is decreased in schizophrenia, but not in depression," Molecular Psychiatry, vol. 11, no. 5, pp. 514-522, 2006.

[77] M. Boldrini, M. D. Underwood, R. Hen et al., "Antidepressants increase neural progenitor cells in the human hippocampus," Neuropsychopharmacology, vol. 34, no. 11, pp. 2376-2389, 2009.

[78] H. B. van der Worp, D. W. Howells, E. S. Sena et al., "Can animal models of disease reliably inform human studies?" PLoS Medicine, vol. 7, no. 3, Article ID e1000245, 2010.

[79] J. Fuss, N. M. B. Ben Abdallah, F. W. Hensley, K. J. Weber, R. Hellweg, and P. Gass, "Deletion of runninginduced hippocampal neurogenesis by irradiation prevents development of an anxious phenotype in mice," PLOS ONE, vol. 5, no. 9, Article ID 12769, 2010.

[80] M. N. Jayatissa, K. Henningsen, M. J. West, and O. Wiborg, "Decreased cell proliferation in the dentate gyrus does not associate with development of anhedonic-like symptoms in rats," Brain Research, vol. 1290, pp. 133-141, 2009.

[81] J. M. Revest, D. Dupret, M. Koehl et al., "Adult hippocampal neurogenesis is involved in anxiety-related behaviors," Molecular Psychiatry, vol. 14, no. 10, pp. 959-967, 2009. 
[82] J. S. Snyder, A. Soumier, M. Brewer, J. Pickel, and H. A. Cameron, "Adult hippocampal neurogenesis buffers stress responses and depressive behaviour," Nature, vol. 476, no. 7361, pp. 458-461, 2011.

[83] G. L. Ming and H. Song, "Adult neurogenesis in the mammalian brain: significant answers and significant questions," Neuron, vol. 70, no. 4, pp. 687-702, 2011.

[84] D. H. R. Blackwood, A. Fordyce, M. T. Walker, D. M. St Clair, D. J. Porteous, and W. J. Muir, "Schizophrenia and affective disorders - cosegregation with a translocation at chromosome 1q42 that directly disrupts brain-expressed genes: clinical and P300 findings in a family," American Journal of Human Genetics, vol. 69, no. 2, pp. 428-433, 2001.

[85] K. Ishizuka, M. Paek, A. Kamiya, and A. Sawa, "A review of disrupted-in-schizophrenia-1 (DISC1): neurodevelopment, cognition, and mental conditions," Biological Psychiatry, vol. 59, no. 12, pp. 1189-1197, 2006.

[86] C. P. Austin, B. Ky, L. Ma, J. A. Morris, and P. J. Shughrue, "Expression of disrupted-in-schizophrenia-1, a schizophrenia-associated gene, is prominent in the mouse hippocampus throughout brain development," Neuroscience, vol. 124, no. 1, pp. 3-10, 2004.

[87] I. L. Schurov, E. J. Handford, N. J. Brandon, and P. J. Whiting, "Expression of disrupted in schizophrenia 1 (DISC1) protein in the adult and developing mouse brain indicates its role in neurodevelopment," Molecular Psychiatry, vol. 9, no. 12, pp. 1100-1110, 2004.

[88] J. Y. Kim, X. Duan, C. Y. Liu et al., "DISC1 regulates new neuron development in the adult brain via modulation of AKT-mTOR signaling through KIAA1212," Neuron, vol. 63, no. 6, pp. 761-773, 2009.

[89] D. Kamnasaran, W. J. Muir, M. A. Ferguson-Smith, and D. W. Cox, "Disruption of the neuronal PAS3 gene in a family affected with schizophrenia," Journal of Medical Genetics, vol. 40, no. 5, pp. 325-332, 2003.

[90] B. S. Pickard, A. Christoforou, P. A. Thomson et al., "Interacting haplotypes at the NPAS3 locus alter risk of schizophrenia and bipolar disorder," Molecular Psychiatry, vol. 14, no. 9, pp. 874-884, 2009.

[91] M. Nyffeler, U. Meyer, B. K. Yee, J. Feldon, and I. Knuesel, "Maternal immune activation during pregnancy increases limbic GABAA receptor immunoreactivity in the adult offspring: implications for schizophrenia," Neuroscience, vol. 143 , no. 1, pp. 51-62, 2006.

[92] C. D. Mandyam and G. F. Koob, “The addicted brain craves new neurons: putative role for adult-born progenitors in promoting recovery," Trends in Neurosciences, vol. 35, no. 4, pp. 250-260, 2012.

[93] R. C. Pierce and V. Kumaresan, "The mesolimbic dopamine system: the final common pathway for the reinforcing effect of drugs of abuse?" Neuroscience and Biobehavioral Reviews, vol. 30, no. 2, pp. 215-238, 2006.

[94] A. J. Eisch, M. Barrot, C. A. Schad, D. W. Self, and E. J. Nestler, "Opiates inhibit neurogenesis in the adult rat hippocampus," Proceedings of the National Academy of Sciences of the United States of America, vol. 97, no. 13, pp. 7579-7584, 2000.

[95] D. N. Abrous, W. Adriani, M. F. Montaron et al., "Nicotine self-administration impairs hippocampal plasticity," The Journal of Neuroscience, vol. 22, no. 9, pp. 3656-3662, 2002.

[96] C. D. Mandyam, S. Wee, E. F. Crawford, A. J. Eisch, H. N. Richardson, and G. F. Koob, "Varied access to intravenous methamphetamine self-administration differentially alters adult hippocampal neurogenesis," Biological Psychiatry, vol. 64, no. 11, pp. 958-965, 2008.
[97] S. A. Lloyd, Z. R. Balest, F. S. Corotto, and R. J. Smeyne, "Cocaine selectively increases proliferation in the adult murine hippocampus," Neuroscience Letters, vol. 485, no. 2, pp. 112-116, 2010.

[98] A. J. Eisch, "Adult neurogenesis: implications for psychiatry," Progress in Brain Research, vol. 138, pp. 315-342, 2002.

[99] M. L. Mustroph, D. J. Stobaugh, D. S. Miller, E. K. DeYoung, and J. S. Rhodes, "Wheel running can accelerate or delay extinction of conditioned place preference for cocaine in male C57BL/6J mice, depending on timing of wheel access," The European Journal of Neuroscience, vol. 34, no. 7, pp. 11611169, 2011.

[100] M. A. Noonan, S. E. Bulin, D. C. Fuller, and A. J. Eisch, "Reduction of adult hippocampal neurogenesis confers vulnerability in an animal model of cocaine addiction," The Journal of Neuroscience, vol. 30, no. 1, pp. 304-315, 2010.

[101] I. Agartz, R. Momenan, R. R. Rawlings, M. J. Kerich, and D. W. Hommer, "Hippocampal volume in patients with alcohol dependence," Archives of General Psychiatry, vol. 56, no. 4, pp. 356-363, 1999.

[102] O. Bengochea and L. M. Gonzalo, "Effect of chronic alcoholism on the human hippocampus," Histology and Histopathology, vol. 5, no. 3, pp. 349-357, 1990.

[103] E. V. Sullivan, L. Marsh, D. H. Mathalon, K. O. Lim, and A. Pfefferbaum, "Anterior hippocampal volume deficits in nonamnesic, aging chronic alcoholics," Alcoholism, vol. 19, no. 1, pp. 110-122, 1995.

[104] S. A. Morris, D. W. Eaves, A. R. Smith, and K. Nixon, "Alcohol inhibition of neurogenesis: a mechanism of hippocampal neurodegeneration in an adolescent alcohol abuse model," Hippocampus, vol. 20, no. 5, pp. 596-607, 2010.

[105] S. S. Newton, E. F. Collier, J. Hunsberger et al., "Gene profile of electroconvulsive seizures: induction of neurotrophic and angiogenic factors," The Journal of Neuroscience, vol. 23, no. 34, pp. 10841-10851, 2003.

[106] M. Nibuya, S. Morinobu, and R. S. Duman, "Regulation of BDNF and trkB mRNA in rat brain by chronic electroconvulsive seizure and antidepressant drug treatments," The Journal of Neuroscience, vol. 15, no. 11, pp. 7539-7547, 1995.

[107] K. Nixon, S. A. Morris, D. J. Liput, and M. L. Kelso, "Roles of neural stem cells and adult neurogenesis in adolescent alcohol use disorders," Alcohol, vol. 44, no. 1, pp. 39-56, 2010.

[108] M. H. Jang, M. C. Shin, E. H. Kim, and C. J. Kim, "Acute alcohol intoxication decreases cell proliferation and nitric oxide synthase expression in dentate gyrus of rats," Toxicology Letters, vol. 133, no. 2-3, pp. 255-262, 2002.

[109] M. Roberto, T. E. Nelson, C. L. Ur, and D. L. Gruol, "Long-term potentiation in the rat hippocampus is reversibly depressed by chronic intermittent ethanol exposure," Journal of Neurophysiology, vol. 87, no. 5, pp. 2385-2397, 2002.

[110] L. J. Santín, S. Rubio, A. Begega, and J. L. Arias, "Effects of chronic alcohol consumption on spatial reference and working memory tasks," Alcohol, vol. 20, no. 2, pp. 149-159, 2000.

[111] D. W. Walker and G. Freund, "Impairment of shuttle box avoidance learning following prolonged alcohol consumption in rats," Physiology \& Behavior, vol. 7, no. 5, pp. 773-778, 1971.

[112] M. M. Husain, A. J. Rush, M. Fink et al., "Speed of response and remission in major depressive disorder with acute electroconvulsive therapy (ECT): a consortium for research in ECT (CORE) report," The Journal of Clinical Psychiatry, vol. 65, no. 4, pp. 485-491, 2004. 
[113] P. G. Janicak, J. M. Davis, R. D. Gibbons et al., "Efficacy of ECT: a meta-analysis," The American Journal of Psychiatry, vol. 142, no. 3, pp. 297-302, 1985.

[114] J. L. Warner-Schmidt, T. M. Madsen, and R. S. Duman, "Electroconvulsive seizure restores neurogenesis and hippocampus-dependent fear memory after disruption by irradiation," European Journal of Neuroscience, vol. 27, no. 6, pp. 1485-1493, 2008.

[115] C. Stewart and I. Reid, "Electroconvulsive stimulation and synaptic plasticity in the rat," Brain Research, vol. 620, no. 1, pp. 139-141, 1993.

[116] E. Bruel-Jungerman, S. Davis, C. Rampon, and S. Laroche, "Long-term potentiation enhances neurogenesis in the adult dentate gyrus," The Journal of Neuroscience, vol. 26, no. 22, pp. 5888-5893, 2006.

[117] R. P. Gwinn, A. Kondratyev, and K. Gale, "Time-dependent increase in basic fibroblast growth factor protein in limbic regions following electroshock seizures," Neuroscience, vol. 114, no. 2, pp. 403-409, 2002.

[118] A. N. Brooks, E. Kilgour, and P. D. Smith, "Molecular pathways: fibroblast growth factor signaling: a new therapeutic opportunity in cancer," Clinical Cancer Research, vol. 18, no. 7, pp. 1855-1862, 2012.

[119] J. M. Hebert, "FGFs: neurodevelopment's Jack-of-all-trades —how do they do it?" Frontiers in Neuroscience, vol. 5, p. 133, 2011.

[120] Y. Shirayama, A. C. H. Chen, S. Nakagawa, D. S. Russell, and R. S. Duman, "Brain-derived neurotrophic factor produces antidepressant effects in behavioral models of depression," The Journal of Neuroscience, vol. 22, no. 8, pp. 3251-3261, 2002.

[121] M. Elsayed, M. Banasr, V. Duric, N. M. Fournier, P. Licznerski, and R. S. Duman, "Antidepressant effects of fibroblast growth factor-2 in behavioral and cellular models of depression," Biological Psychiatry, vol. 72, no. 4, pp. 258$265,2012$.

[122] D. Taliaz, N. Stall, D. E. Dar, and A. Zangen, "Knockdown of brain-derived neurotrophic factor in specific brain sites precipitates behaviors associated with depression and reduces neurogenesis," Molecular Psychiatry, vol. 15, no. 1, pp. 80-92, 2010.

[123] M. H. Maurer, W. K. Tripps, R. E. Feldmann Jr., and W. Kuschinsky, "Expression of vascular endothelial growth factor and its receptors in rat neural stem cells," Neuroscience Letters, vol. 344, no. 3, pp. 165-168, 2003.

[124] A. M. Lozano and C. Hamani, "The future of deep brain stimulation," Journal of Clinical Neurophysiology, vol. 21, no. 1, pp. 68-69, 2004.

[125] A. M. Lozano, H. S. Mayberg, P. Giacobbe, C. Hamani, R. C. Craddock, and S. H. Kennedy, "Subcallosal cingulate gyrus deep brain stimulation for treatment-resistant depression," Biological Psychiatry, vol. 64, no. 6, pp. 461-467, 2008.

[126] H. S. Mayberg, A. M. Lozano, V. Voon et al., "Deep brain stimulation for treatment-resistant depression," Neuron, vol. 45, no. 5, pp. 651-660, 2005.

[127] B. H. Bewernick, R. Hurlemann, A. Matusch et al., "Nucleus accumbens deep brain stimulation decreases ratings of depression and anxiety in treatment-resistant depression," Biological Psychiatry, vol. 67, no. 2, pp. 110-116, 2010.

[128] R. Silva, A. R. Mesquita, J. Bessa et al., "Lithium blocks stress-induced changes in depressive-like behavior and hippocampal cell fate: the role of glycogen-synthase-kinase-3 $\beta$," Neuroscience, vol. 152, no. 3, pp. 656-669, 2008.
[129] M. Sairanen, G. Lucas, P. Ernfors, M. Castrén, and E. Castrén, "Brain-derived neurotrophic factor and antidepressant drugs have different but coordinated effects on neuronal turnover, proliferation, and survival in the adult dentate gyrus," The Journal of Neuroscience, vol. 25, no. 5, pp. 1089-1094, 2005.

[130] F. L. Neto, G. Borges, S. Torres-Sanchez, J. A. Mico, and E. Berrocoso, "Neurotrophins role in depression neurobiology: a review of basic and clinical evidence," Current Neuropharmacology, vol. 9, no. 4, pp. 530-552, 2011.

[131] T. Saarelainen, P. Hendolin, G. Lucas et al., "Activation of the TrkB neurotrophin receptor is induced by antidepressant drugs and is required for antidepressant-induced behavioral effects," The Journal of Neuroscience, vol. 23, no. 1, pp. 349357, 2003.

[132] Y. Li, B. W. Luikart, S. Birnbaum et al., “TrkB regulates hippocampal neurogenesis and governs sensitivity to antidepressive treatment," Neuron, vol. 59, no. 3, pp. 399-412, 2008.

[133] J. L. Warner-Schmidt and R. S. Duman, "VEGF is an essential mediator of the neurogenic and behavioral actions of antidepressants," Proceedings of the National Academy of Sciences of the United States of America, vol. 104, no. 11, pp. 4647-4652, 2007.

[134] T. D. Palmer, E. A. Markakis, A. R. Willhoite, F. Safar, and F. H. Gage, "Fibroblast growth factor-2 activates a latent neurogenic program in neural stem cells from diverse regions of the adult CNS," The Journal of Neuroscience, vol. 19, no. 19, pp. 8487-8497, 1999.

[135] H. van Praag, B. R. Christie, T. J. Sejnowski, and F. H. Gage, "Running enhances neurogenesis, learning, and long-term potentiation in mice," Proceedings of the National Academy of Sciences of the United States of America, vol. 96, no. 23, pp. 13427-13431, 1999.

[136] K. van der Borght, R. Havekes, T. Bos, B. J. L. Eggen, and E. A. van der Zee, "Exercise improves memory acquisition and retrieval in the Y-maze task: relationship with hippocampal neurogenesis," Behavioral Neuroscience, vol. 121, no. 2, pp. 324-334, 2007.

[137] K. I. Erickson, M. W. Voss, R. S. Prakash et al., "Exercise training increases size of hippocampus and improves memory," Proceedings of the National Academy of Sciences of the United States of America, vol. 108, no. 7, pp. 3017-3022, 2011.

[138] T. W. Scheewe, F. J. Backx, T. Takken et al., "Exercise therapy improves mental and physical health in schizophrenia: a randomised controlled trial," Acta Psychiatrica Scandinavica. In press.

[139] P. Bekinschtein, C. A. Oomen, L. M. Saksida, and T. J. Bussey, "Effects of environmental enrichment and voluntary exercise on neurogenesis, learning and memory, and pattern separation: BDNF as a critical variable?" Seminars in Cell \& Developmental Biology, vol. 22, no. 5, pp. 536-542, 2011.

[140] J. Farmer, X. Zhao, H. van Praag, K. Wodtke, F. H. Gage, and B. R. Christie, "Effects of voluntary exercise on synaptic plasticity and gene expression in the dentate gyrus of adult male sprague-dawley rats in vivo," Neuroscience, vol. 124, no. 1, pp. 71-79, 2004.

[141] S. A. Neeper, F. Gómez-Pinilla, J. Choi, and C. W. Cotman, "Physical activity increases mRNA for brain-derived neurotrophic factor and nerve growth factor in rat brain," Brain Research, vol. 726, no. 1-2, pp. 49-56, 1996.

[142] M. Bergami, R. Rimondini, S. Santi, R. Blum, M. Götz, and M. Canossa, "Deletion of TrkB in adult progenitors alters newborn neuron integration into hippocampal circuits and increases anxiety-like behavior," Proceedings of the National 
Academy of Sciences of the United States of America, vol. 105, no. 40, pp. 15570-15575, 2008.

[143] S. Vaynman, Z. Ying, and F. Gomez-Pinilla, "Interplay between brain-derived neurotrophic factor and signal transduction modulators in the regulation of the effects of exercise on synaptic-plasticity," Neuroscience, vol. 122, no. 3, pp. 647657, 2003. 

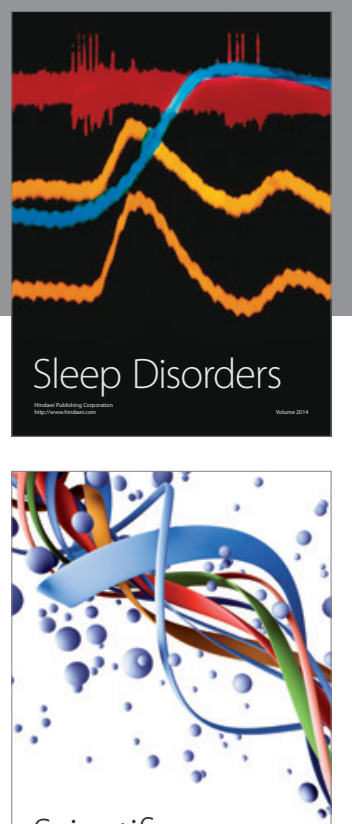

Scientifica
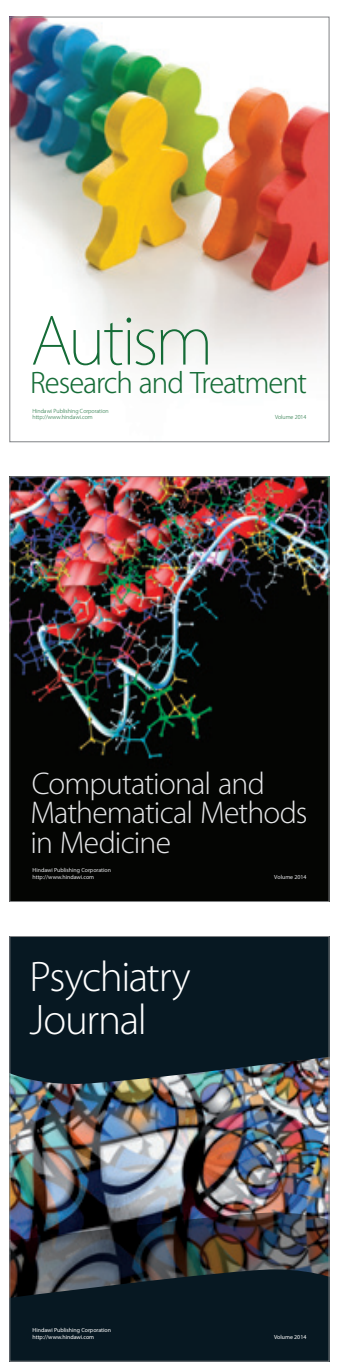
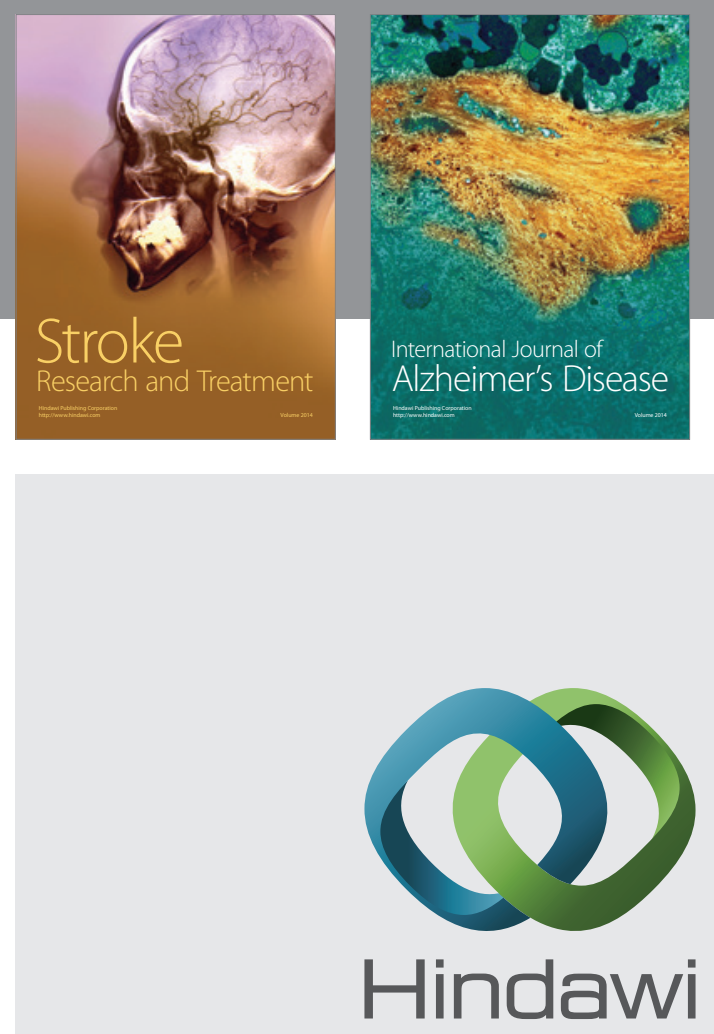

Submit your manuscripts at

http://www.hindawi.com
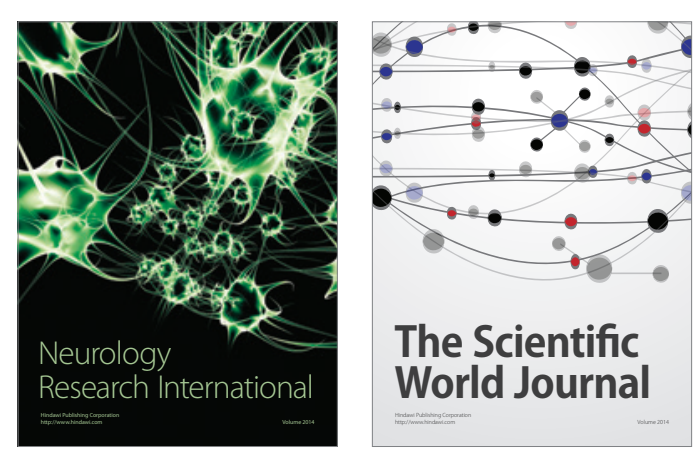

The Scientific World Journal

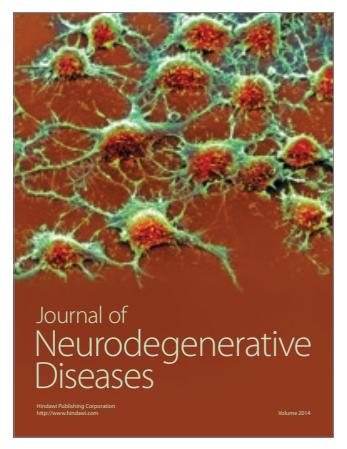

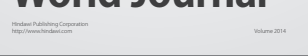

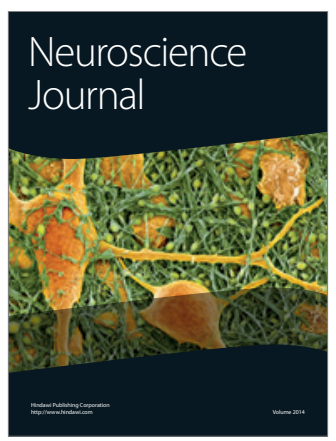

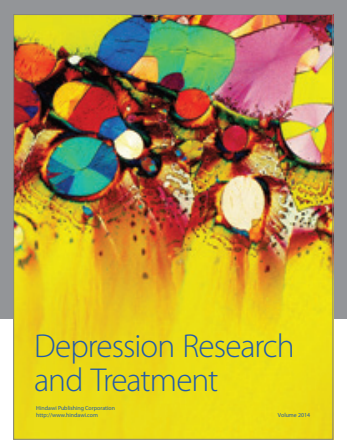
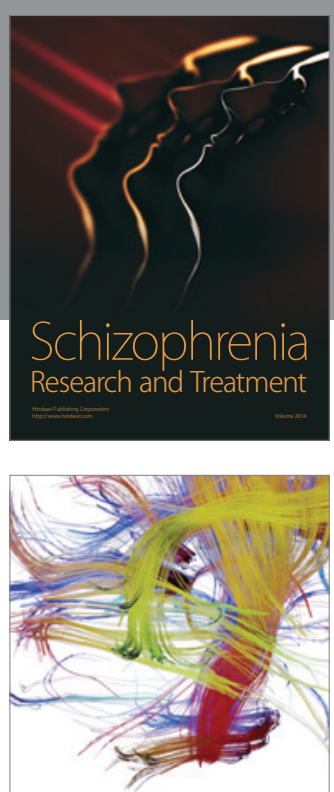

Brain Science

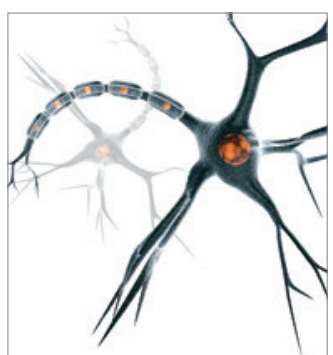

Neural Plasticity
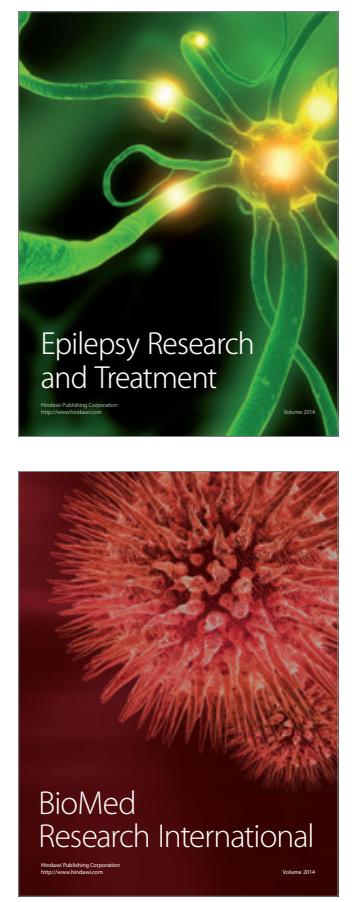

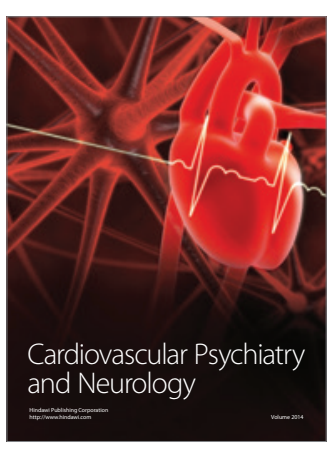

Parkinson's

Disease
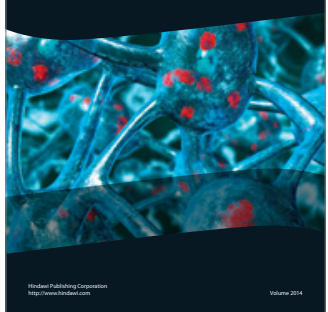